Elsevier required licence: (C) <2017>. This manuscript version is made available under the CC-BY-NC-ND 4.0 license http://creativecommons.org/licenses/by-nc-nd/4.0/ 


\section{Nanofiltration applications of tough MWNT buckypaper membranes containing biopolymers}

Md. Harun-Or Rashid, ${ }^{\mathrm{a}}$ Gerry Triani, ${ }^{\mathrm{b}}$ Nicholas Scales, ${ }^{\mathrm{b}}$ Marc in het Panhuis, ${ }^{\mathrm{c}}$ Long D. Nghiem $^{\mathrm{d}}$ and Stephen F. Ralph ${ }^{\mathrm{a}^{*}}$

\footnotetext{
${ }^{a}$ School of Chemistry, University of Wollongong, Australia

${ }^{\mathrm{b}}$ Australian Nuclear Science and Technology Organisation, Lucas Heights, Australia

${ }^{c}$ Soft Materials Group, School of Chemistry and ARC Centre of Excellence for

Electromaterials Science, AIIM Facility, University of Wollongong, Australia

${ }^{\mathrm{d}}$ Strategic Water Infrastructure Laboratory, School of Civil, Mining and Environmental Engineering, University of Wollongong, Australia

* Corresponding author
}

Email addresses:

mhor972@uowmail.edu.au (M. H. O. Rashid)

gerry.triani@ansto.gov.au (G. Triani)

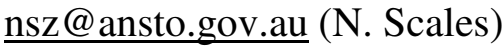

panhuis@uow.edu.au (M. in het Panhuis)

longn@uow.edu.au (L. D. Nghiem)

sralph@uow.edu.au (S. F. Ralph). 


\section{ABSTRACT}

The ability of biopolymers (bovine serum albumin, lysozyme, chitosan, gellan gum and DNA) to facilitate formation of aqueous dispersions of MWNTs was investigated using a combination of absorption spectrophotometry and optical microscopy. Subsequently, selfsupporting carbon nanotube membranes, known as buckypapers (BPs), were prepared by vacuum filtration of the dispersions. Microanalytical data obtained from the BPs confirmed the retention of biopolymers within their structures. Tensile test measurements performed on the BPs showed that incorporation of the biopolymers resulted in significant improvements in mechanical properties, compared to analogous BPs containing MWNTs and the low molecular mass dispersant Triton X-100. For example, MWNT/CHT BPs $(\mathrm{CHT}=$ chitosan $)$ exhibited values for tensile strength, ductility, Young's modulus and toughness of $28 \pm 2$ $\mathrm{MPa}, 5.3 \pm 2.7 \%, 0.9 \pm 0.3 \mathrm{GPa}$ and $1.7 \pm 0.3 \mathrm{~J} / \mathrm{g}$, respectively. Each of these values are significantly greater than those obtained for MWNT/Trix, prepared using a low molecular weight dispersant $(6 \pm 3 \mathrm{MPa}, 1.3 \pm 0.2 \%, 0.6 \pm 0.3 \mathrm{GPa}$ and $0.10 \pm 0.06 \mathrm{~J} / \mathrm{g}$, respectively). This significant improvement in mechanical properties is attributed to the ability of the long biopolymer molecules to act as flexible bridges between the short CNTs. All BPs possessed hydrophilic surfaces, with contact angles ranging from $29 \pm 2$ to $57 \pm 5^{\circ}$. Nitrogen gas porosimetry showed that the BPs have highly porous internal structures, while scanning electron microscopy (SEM) of their surface morphologies showed numerous pore openings. The permeability of these BPs towards water, inorganic salts, and dissolved trace organic contaminants (TrOCs), such as pharmaceuticals, personal care products, and pesticides was investigated through filtration experiments. Of the twelve TrOCs investigated in this study, nine compounds were rejected by more than $95 \%$ by BPs composed of MWNTs and chitosan. The latter BPs also demonstrated good rejection of both $\mathrm{NaCl}$ (30 to 55\%) and $\mathrm{MgSO}_{4}(40$ to $70 \%)$. 
Keywords: CNTs, biopolymers, buckypapers, water permeability, trace organic contaminants, salt rejections. 


\section{Introduction}

The presence of trace organic contaminants (TrOCs), including pharmaceuticals, pesticides, personal care products, and various industrial compounds, in the environment is of great concern due to their potential adverse effects on human health and the ecosystem [1-3]. TrOCs have been routinely detected in municipal wastewater and sewage-impacted natural water supplies at concentrations ranging from $n g \mathrm{~L}^{-1}$ to $\mu \mathrm{g} \mathrm{L}^{-1}[1,4]$. Therefore, it is essential to develop highly effective methods for removing these contaminants to protect the environment and ensure provision of safe drinking water. Previous studies showed that reverse osmosis (RO) and nanofiltration (NF) membranes are able to achieve high removal efficiencies (>90\%) with most TrOCs, particularly those that are negatively charged or have high molecular weights [5-8]. A major disadvantage of current membranes used for filtration techniques, however, is that they require a high driving force for operation, which increases costs and limits their area of application. Membrane fouling is also an issue during RO operation and is caused by the presence of particulates, dissolved organic matter, and organic compounds in water supplies $[9,10]$.

Another common method for removal of TrOCs is adsorption using activated carbon. The potential of activated carbon for the removal of pesticides and other TrOCs, including a range of pharmaceuticals, has also been demonstrated [11-14]. However, in some studies the results obtained have not been optimal, as the adsorption capacity of the activated carbon has varied significantly from one TrOC to another [12]. A further potential drawback to the use of activated carbon for removal of TrOCs is that its effectiveness can decrease when bulk organic matter is also present, as the latter can compete for adsorptive sites and block pores within the structure of the activated carbon $[11,15]$. 
Owing to the limitations noted above when using current NF/RO membranes or activated carbon for the removal of TrOCs, researchers continue to search for new materials to improve upon current water purification processes. One promising material is carbon nanotubes (CNTs), which have attracted a great deal of interest in recent years for a number of applications, owing to their unique combination of electronic, mechanical and thermal properties [16-18]. For example, membranes composed of either aligned arrays of CNTs, or randomly entangled networks of CNTs, have been examined for their potential to be used as membrane filtration media. In one study, aligned multi-walled carbon nanotube (MWNT) membranes with internal diameters of $6.5 \mathrm{~nm}$ were prepared and found to allow the passage of $\left[\mathrm{Ru}(\mathrm{bpy})_{3}\right]^{2+}\left(\mathrm{bpy}=2,2^{\prime}\right.$-bipyridine $)$ molecules and gold nanoparticles with average diameters of 2 and $5 \mathrm{~nm}$, but not larger gold nanoparticles with an average diameter of $10 \mathrm{~nm}$ [19]. In another study, macroscopic hollow cylinders composed of radially aligned MWNTs were shown to retain the heavier components of a hydrocarbon mixture, as well as bacteria and viruses present in contaminated solutions [20]. Whilst these are promising results, there are some disadvantages associated with using membranes prepared from aligned CNTs. These include low porosities $(0.5-2.7 \%)$ and complex preparation methods $[19,21]$. For example, aligned arrays of CNTs must often be removed from an underlying substrate using vigorous chemical etching methods, that require hazardous reagents such as HF [22].

BPs are a simpler type of membrane architecture, and consist of a self-supporting entangled assembly of CNTs. BPs are flexible materials, but they can also exhibit a significant degree of chemical and physical stability $[23,24]$. The pores present in BPs contribute $60-70 \%$ of their total volume, making them attractive for filtration purposes [25]. However, to date, very few studies have investigated the filtration properties of BP membranes. Brady-Estévez and coworkers showed that BPs can be highly effective for removing bacteria and viruses from 
water [26,27]. Their initial study employed BPs prepared by depositing SWNTs onto a piece of polyvinylidene fluoride (PVDF). In a subsequent study, they demonstrated effective removal of E. coli and bacteriophage MS2 from water samples by this SWNT membrane [26]. Several other studies have shown that CNTs exhibit strong antimicrobial properties $[28,29]$. It was shown that the direct cell (E. coli bacteria) contact with SWNTs caused severe membrane damage and subsequent cell inactivation by physically penetrating through the living cells $[28,29]$. Recent interest in CNTs also stems from research that showed they can be used to improve the antifouling properties of commercial UF membranes [30,31]. For example, Celik et al. investigated protein fouling behaviour of MWNTs/polyethersulfone (PES) composite membranes during water filtration and showed that the MWNT/PES composite membranes were fouled less compared to the pure PES membrane when filtering bovine serum albumin (BSA) and ovalbumin (OVA) [30]. Bai et al. also explored antifouling properties of MWNT/PES composite membranes towards natural organic matter (humic acid, BSA, sodium alginate) [31]. The application of self-supported BPs prepared from MWNT dispersion in propan-2-ol for membrane distillation has also been recently demonstrated by Dumee et al. [32].

Recently we measured the permeability towards water, and determined the effectiveness for bacterial filtration, of self-supporting (i.e. without an underlying PVDF support) BPs that had been prepared from aqueous dispersions of SWNTs that also contained macrocyclic ligands or antibiotics [33,34]. These BPs could remove $99 \%$ of the E. coli from an aqueous suspension [34], providing evidence that free-standing membranes of this type are as effective for removing microbial contaminants from water supplies as the composite CNT materials investigated previously [26,27]. Subsequently we also showed that over 90\% removal of bisphenol $\mathrm{A}$ (BPA) and other TrOCs present in aqueous samples could be 
achieved using self-supporting MWNT BPs prepared from dispersions made with Triton X100 [35]. Additional evidence that BPs can be useful for water purification applications was provided by Harris and co-workers [36]. These researchers constructed membranes from MWNT dispersions prepared in ethanol, without the assistance of a surfactant or other dispersant. Their BPs were very effective for the removal of humic acid (>93\%) from water samples [37].

Further support for the potential of BPs as filtration media for removal of TrOCs and other classes of contaminants has been provided by a number of recent investigations involving raw CNTs themselves, in which the latter materials were shown to have high adsorption capacities for phenols, heavy metals, and natural organic matter [38-41]. Several workers have suggested that CNTs may be more effective adsorbents than activated carbon for removing organic compounds, due to the larger specific surface area of nanotubes, and diverse range of contaminant/adsorbent interactions they can participate in $[42,43]$.

The above investigations involving raw CNTs provide impetus for further studies into the effectiveness of BPs for removal or recovery of dissolved pollutants from water supplies. However, in order for BPs to become attractive options for such applications, it is essential to improve their mechanical properties, as they are often brittle due to weak connections between nanotube bundles. One method for overcoming this issue is to reinforce the BPs, e.g. by polymer intercalation $[44,45]$. For example, Coleman et al. infiltrated PVA, polyvinyl pyrrolidone (PVP), and polystyrene (PS) into BPs Harun, add reference 45 here again. They found that this resulted in increases in Young's modulus, tensile strength, toughness, and strain to break for the infiltrated BPs. It was also demonstrated that the intercalation of 
high molecular weight polymers was better for improving the modulus and strength of BPs, while low molecular weight polymers resulted in greater overall toughness. A similar approach to enhancing the strength of BPs was adopted by Dumee et al. [Desalination and Water Treatment, 17, 72-79 (2010)]. These authors "infiltrated" MWNT BPs prepared without the assistance of a dispersant, using polystyrene or polyvinylidene fluoride. Both types of memebranes showed superior aqueous permeability and salt rejection properties compared to the BPs alone.

A variety of other methods have also been employed to afford CNT/polymer composite materials that exhibit improved mechanical properties compared to free-standing BPs, but generally retain the porosity of the latter. These include sputter coating a BP with poly(tetrafluoroethylene) [Desalination, 283, 64-67 (2011)], covalent attachment of alkoxysilane groups to the CNTs prior to dispersion and BP fabrication [J Membr Sci 376, 241-246 (2011)] and deposition of a polyamide layer onto a fee-standing BP [J Membr Sci 427, 422-430 (2013)]. In addition, composite membranes with improved mechanical properties and filtration characteristics have been prepared by sandwiching BPs between polypropylene layers and applying high temperatures and pressures, and by filtering CNT dispersions through the pores of conventional organic polymers [Desalination and Water Treatment, 17, 72-79 (2010)].

We have recently showed that BPs prepared from aqueous dispersions of SWNTs, that also contained biopolymers, exhibit superior mechanical properties compared to analogous membranes made from dispersions that contained low molecular mass surfactants [46]. In view of these results, and the potential for the biopolymer molecules trapped within BPs to 
interact by a variety of mechanisms with dissolved solutes, we decided to explore the potential of membranes prepared from aqueous dispersions containing MWNTs and different biopolymers, for removing selected TrOCs and simple salts from aqueous solutions. Multiwalled carbon nanotubes were chosen for this initial investigation owing to their lower cost and greater ease of dispersion.

\section{Materials and methods}

\subsection{Reagents}

MWNTs (purity $>95 \%$, average diameter $9.5 \mathrm{~nm}$, average length $1.5 \mu \mathrm{m}$ ) produced by chemical vapour deposition were purchased from Nanocyl S.A., Belgium (Nanocyl-3100) and used without further purification. Low molecular weight chitosan (CHT; batch no. MKBB4232), bovine serum albumin (BSA; fraction $\mathrm{V}, \geq 96 \%$, batch no. 067K0759), lysozyme (LSZ; protein $\geq 90 \%$, lot no. 100M1897V), and deoxyribonucleic acid (DNA) sodium salt were purchased from Sigma-Aldrich. CP Kelco provided food grade low-acyl gellan gum (GG; Kelcogel ${ }^{\circledR}$, batch no. 7C9228A) for use in this study. Unless otherwise specified, all solutions containing MWNTs and dispersants were prepared in Milli-Q ${ }^{\circledR}$ water (resistivity $18.2 \mathrm{M} \Omega \mathrm{cm}$ ). In the case of chitosan solutions, $0.01 \%(\mathrm{v} / \mathrm{v})$ acetic acid (AR grade, Ajax) was added to solubilise the dispersant. Analytical grade amitriptyline, trimethoprim, sulfamethoxazole, diclofenac, bezafibrate, caffeine, atrazine, primidone, carbamazepine, pentachlorophenol, linuoron and triclosan from Sigma-Aldrich were used as model TrOCs. Other solvents used in this study included methanol (99.8\%, Merck), ethanol (absolute, Ajax) and acetone (99.5\%, Ajax). 


\subsection{Preparation of MWNT/biopolymer dispersions}

All dispersions in this study were prepared using Milli- ${ }^{\circledR}$ water, unless specified otherwise, and contained MWNTs with a concentration of $0.1 \%(\mathrm{w} / \mathrm{v})$. The concentrations of biopolymers used for preparing dispersions were $0.05 \%(\mathrm{w} / \mathrm{v})$ in the case of chitosan, gellan gum and DNA, while for the two protein dispersants (lysozyme and bovine serum albumin) $0.2 \%(\mathrm{w} / \mathrm{v})$ was used instead. In a typical experiment, $15 \mathrm{mg}$ of MWNTs were dispersed in $15 \mathrm{~mL}$ of dispersant solution using a Branson 450 (400 W, Ultrasonics Corp.) digital sonicator horn with a probe diameter of $10 \mathrm{~mm}$ to apply ultrasonic energy. The conditions used were amplitude of $30 \%, 16 \mathrm{~W}$ (measured) power output, pulse duration of $0.5 \mathrm{~s}$ and pulse delay of $0.5 \mathrm{~s}$. The minimum sonication time required for complete dispersion of all MWNTs in a typical sample was 10 min. During sonication, the sample vial was placed inside an ice/water bath to maintain a stable temperature. The only exception to this was with gellan gum and the sample vial was placed in a warm water (c.a. $50{ }^{0} \mathrm{C}$ ) bath to prevent gelation.

\subsection{Preparation of MWNT BPs composed of biopolymers}

Dispersions of MWNTs were converted into BP membranes using vacuum filtration. Depending on the filtration apparatus used, two different sized BPs were obtained. Small, circular BPs measuring approximately $35 \mathrm{~mm}$ in diameter were obtained using the following procedure. Two dispersions prepared as described in section 2.2 were combined, and added to a further $50 \mathrm{~mL}$ of dispersant solution $(0.05 \%(\mathrm{w} / \mathrm{v})$ chitosan, gellan gum or DNA, or $0.2 \%$ (w/v) BSA or LSZ), and then placed in an ultrasonic bath (Unisonics, 50Hz, 150W) for 3 min. This process resulted in homogeneous dispersions $(80 \mathrm{~mL})$ containing $0.038 \%(\mathrm{w} / \mathrm{v})$ MWNTs. Milli-Q ${ }^{\circledR}$ water was added to give a total volume of $250 \mathrm{~mL}$ (final MWNT concentration after dilution $0.012 \%(\mathrm{w} / \mathrm{v}))$, and the resulting dispersion was then vacuum 
filtered through a (polytetrafluoroethylene) (PTFE) membrane filter (5 $\mu \mathrm{m}$ pore size; Millipore) housed in an Aldrich glass filtration unit, using a Vacuubrand CVC2 pump that typically operated between 30 and 50 mbar. Plastic film was placed over the tops of the filtration units to minimise evaporative losses during the filtration process.

Large BPs used for physical characterisation testing, as well as water permeability and TrOC rejection experiments, were prepared using a custom made rectangular filtration cell containing an internal sintered glass frit measuring $5.5 \mathrm{~cm} \times 8 \mathrm{~cm}$. Initially six identical dispersions were prepared as described in Section 2.2, and then added to $50 \mathrm{~mL}$ of dispersant solution containing the same biopolymer, but no MWNTs. The resulting mixture was subjected to further treatment in the ultrasonic bath for $3 \mathrm{~min}$. The resulting homogeneous dispersions $(140 \mathrm{~mL})$ contained $0.064 \%(\mathrm{w} / \mathrm{v})$ of MWNTs, and were diluted to a total volume of $1 \mathrm{~L}$ with Milli- $\mathrm{Q}^{\circledR}$ water (final MWNT concentration after dilution $0.009 \%(\mathrm{w} / \mathrm{v})$ ). These final dispersions were filtered across a piece of commercial polyvinylidene fluoride (PVDF) membrane $(0.22 \mu \mathrm{m}$ pore size; Millipore $)$ housed in a custom-made filtration unit. After the filtration process was completed, the buckypaper was washed with $250 \mathrm{~mL}$ of Milli-Q ${ }^{\circledR}$ water and then $10 \mathrm{~mL}$ of methanol (99.8\%, Merck) whilst still in the filtration unit. After washing, the damp BP was allowed to dry overnight after being placed between absorbent paper sheets. The dry BP was then carefully peeled away from the underlying commercial membrane filter.

A second type of rectangular BP $(6 \mathrm{~cm} \times 12 \mathrm{~cm})$ was prepared for use in salt rejection experiments using a custom-built filtration cell. In order to prepare a BP of this size, 10 homogeneous dispersions measuring a total of $150 \mathrm{~mL}$ were required. The combined dispersions were diluted to a total volume of $1 \mathrm{~L}$ with Milli-Q ${ }^{\circledR}$ water (final MWNT concentration after dilution was $0.015 \%(\mathrm{w} / \mathrm{v}))$, before being filtered through large sheets of 
PVDF membrane. The resulting buckypaper was then washed and dried using the same procedure outlined above. All BP samples were stored at room temperature (c.a. $21^{\circ} \mathrm{C}$ ) in sealed glass or plastic petri dishes. Examples of the three different types of BPs used in this study are shown in the Supplementary Data section (Fig. S1).

\subsection{Characterization techniques}

Absorption spectra of all dispersions were obtained between 300 and $1000 \mathrm{~nm}$ using a Cary 500 UV-vis-NIR spectrophotometer and quartz cuvettes. The dispersions were first diluted with Milli- $\mathrm{Q}^{\circledR}$ water to ensure that the measured absorbance values were within the optimal range of the instrument. A Leica Z16 APO LED1000 microscope equipped with a digital camera was used to perform preliminary assessments of the effectiveness of different biopolymer dispersants to produce stable dispersions of MWNTs. Elemental analyses were performed on pristine CNTs and BPs by the Campbell Microanalytical Laboratory, Department of Chemistry, University of Otago, New Zealand. The surface morphology of BPs was examined using a JEOL JSM-7500FA field emission scanning electron microscope (FESEM). The operating voltage of the SEM was $5 \mathrm{kV}$. Samples were cut into small strips and mounted onto a conductive stub using carbon tape or by wedging the sample between a screw mount on the stub itself. All materials were sufficiently conductive to enable images to be obtained without having to first coat them with a metallic or carbon layer. Images obtained by SEM were analysed using Image Pro Plus software to obtain quantitative information about the diameter of surface pores of each BP. The thicknesses of BPs were measured using a Mitutoyo IP65 digital micrometer. Measurements were made at 10 separate points on each BP and averaged to provide a mean thickness. The contact angles of BPs were determined using the sessile drop method and a Data Physics SCA20 goniometer fitted with a digital camera. The contact angles of $2 \mu \mathrm{L}$ Milli- $\mathrm{Q}^{\circledR}$ water droplets on the surfaces of the BPs were 
calculated using the accompanying Data Physics software (SCA20.1). The mean contact angle was calculated using measurements performed on at least five water droplets. The electrical conductivities and mechanical properties of BPs were measured using equipment and methods reported previously $[33,46]$.

The electrical conductivity of BP samples was evaluated using a standard two-point probe method [47]. BP samples were cut into rectangular strips approximately $3 \mathrm{~mm}$ wide and 40 $\mathrm{mm}$ long. The BP strips were fixed onto a small piece of copper tape (3M) adhered to a glass microscope slide using high purity silver paint (SPI) to prepare low resistance contacts. Another glass microscope slide was clamped onto the slide containing the BP strip using bulldog clips to ensure the sample was secure, and a continuous connection during the testing procedure. Experiments were performed by applying a triangular waveform with voltage limits of -0.05 and $0.05 \mathrm{~V}$ to the sample using a waveform generator (Agilent 33220A). Both the current (I) and voltage (V) responses were measured using a multimeter (Agilent 34410A) connected within the simple circuit, and attached to a personal computer recording data points every $1.0 \mathrm{~s}$. This enabled I-V plots to be constructed which could then be used to determine resistance for the length of sample used. Using these resistance values, the conductivity could then be calculated by accounting for the sample thickness, which was measured using a digital micrometre (IP65, Mitutoyo). Measurements were repeated for a minimum of five lengths for each BP strip.

The mechanical properties of BP samples were determined using a Shimadzu EZ-S universal testing device and BP samples cut into small rectangular strips measuring approximately 15 $\mathrm{mm} \times 4 \mathrm{~mm}$ and mounted into a small paper frame. The length of the sample between the top and bottom clamps was kept constant at $10 \mathrm{~mm}$. The paper frame was cut between the clamps prior to testing, and the mounted samples were then stretched using a $50 \mathrm{~N}$ load cell until 
failure occurred. The samples were tested at ambient temperature $\left(\sim 21{ }^{\circ} \mathrm{C}\right)$ with a strain rate of $0.1 \mathrm{~mm}$ min-1. All results were recorded via an attached personal computer using the Trapezium X software package provided with the instrument, and analysed using Microsoft Excel to yield the corresponding stress-strain curves. These stress-strain curves were used to determine the Young's modulus, tensile strength, ductility and toughness of samples.

Nitrogen adsorption-desorption isotherms were obtained at the Australian Nuclear Science and Technology Organisation (ANSTO) using a Micromeritics surface area analyser (ASAP 2020) operating at $77 \mathrm{~K}\left(-196{ }^{\circ} \mathrm{C}\right)$. Prior to analysis, the pristine MWNT sample was degassed at $150{ }^{\circ} \mathrm{C}$ and the buckypapers were all degassed at $120{ }^{\circ} \mathrm{C}$ under vacuum. The resulting isotherms were analysed using the Horvath-Kawazoe (HK) and Barrett, Joyner and Halenda $(\mathrm{BJH})$ methods to determine the distribution of small and large pores, respectively [48,49]. Multipoint Brunauer, Emmett, and Teller (BET) analysis of the isotherms was used to calculate the specific surface areas of the buckypapers [50]. In addition, interbundle pore volumes were calculated according to equation (1), which uses the total $\mathrm{BJH}$ cumulative pore volume $\left(\mathrm{V}_{\mathrm{BJH}}\right)$ and the $\mathrm{HK}$ cumulative pore volume, with the latter summed only to the minimum point between the two pore distributions $\left(\mathrm{V}_{\mathrm{HK}, \mathrm{min}}\right)$ :

$$
\text { Interbundle pore volume }(\%)=\frac{V_{B J H}-V_{H K, \min }}{V_{B J H}} \times 100
$$

\subsection{Permeability studies}

The permeability of BPs towards water was measured using a custom-made dead-end filtration cell setup (Fig. S2). Compressed air was used to induce a trans-membrane pressure and obtain a water flux across individual BPs, which measured $5.5 \mathrm{~cm} \times 8.0 \mathrm{~cm}$ in size. The BP was first placed on porous stainless steel, which provided mechanical support to the 
membrane. Initially a pressure of 1 psi (0.069 bar) was applied to the BP, and the volume of water passing across the membrane was monitored for 10 min using an analytical balance connected to a computer. From the slope of the resulting plot of accumulated permeate volume against time the permeate flux $(J)$ was determined. The pressure applied to the BP was then incrementally increased and the process repeated, affording values of $J$ at several different pressures. This data was then used to determine the BP water permeability $(f)$ using the following equation:

$f=\frac{J}{A \times \Delta P}$

where $A$ is the effective membrane area $\left(\mathrm{m}^{2}\right)$, and $\Delta P$ is the applied pressure difference across the membrane (bar).

The permeability of MWNT/biopolymer BPs towards the mixture of TrOCs was examined using the same dead-end filtration cell (Supplementary Data Fig. S2). Experiments involving TrOCs were performed using four different BPs, and a set of 12 organic compounds that included pharmaceuticals, pesticides and personal care products. These organic compounds are frequently detected in secondary treated effluent and sewage-impacted water bodies at trace levels. A stock solution containing $1 \mathrm{~g} \mathrm{~L}^{-1}$ of each compound was prepared in pure methanol. The stock solution was kept at $-18{ }^{\circ} \mathrm{C}$ in the dark and used within one month of preparation. The stock solution was introduced into the Milli- $\mathrm{Q}^{\circledR}$ feed solution to give a final concentration of each compound of approximately $50 \mu \mathrm{g} \mathrm{L}^{-1}$. The pressures applied to MWNT/BSA, MWNT/LSZ, MWNT/CHT, MWNT/GG and MWNT/DNA BPs at the commencement of experiments were $1.54,1.1,0.69,0.67$ and 1.0 bar, respectively. These pressures were selected as water permeability experiments showed that they would result in a flux of water across all membranes of $5 \mathrm{~L} \mathrm{~m}^{-2} \mathrm{~h}^{-1}$. In all cases, the permeate solutions were 
collected sequentially in six aliquots, each measuring $20 \mathrm{~mL}$. Concentrations of TrOCs in the initial feed, permeate, and retentate (final feed) solution were determined using a Shimadzu LC-MS system (LC-MS 2020) equipped with an electrospray ionisation (ESI) interface. A detailed description of this analytical technique is available elsewhere [51]. The TrOC rejection, $R(\%)$, was calculated from the equation:

$R=1-\frac{C_{p}}{C_{f}} \times 100$

where $C_{f}$ was the solute concentration in the feed solution and $C p$ was the solute concentration in the permeate.

A custom-built cross flow NF/RO filtration system (Supplementary Data Fig. S3) was used to investigate the permeability of selected large BPs $(6.0 \mathrm{~cm} \times 12.0 \mathrm{~cm})$ towards water, as well as towards a mixture containing both the twelve TrOCs used in the above experiments, and two simple salts $\left(\mathrm{NaCl}\right.$ and $\left.\mathrm{MgSO}_{4}\right)$. The system consisted of a rectangular cross-flow cell composed of stainless steel, with an effective membrane filtration area of $40 \mathrm{~cm}^{2}(10 \times 4 \mathrm{~cm})$ and a channel height of $2 \mathrm{~mm}$. The feed solution was contained in a stainless steel $5 \mathrm{~L}$ reservoir, and was fed to the buckypaper membrane housed in the filtration cell by a highpressure pump (HydraCell, Wanner Engineering Inc., Minneapolis, MN, USA). The permeate flow and cross flow solution velocities were regulated by a bypass valve and back-pressure regulator (Swagelok, Solon, OH, USA). A digital flow meter (FlowCal, GJC Instruments Ltd, Cheshire, UK) connected to a PC was used to monitor the permeate flow, and the cross flow was measured using a manual flow meter. The pressure of the feed solution was provided by a pressure gauge, and also recorded during water and solute permeability experiments. Throughout an entire filtration experiment, the temperature of the feed solution was kept constant at $20 \pm 1{ }^{\circ} \mathrm{C}$ using a temperature control unit (Neslab RTE 7, Thermo Scientific Inc., 
Waltham, MA, USA) equipped with a stainless steel heat exchanger coil which was submerged directly into the feed reservoir.

During filtration experiments, Milli- $\mathrm{Q}^{\circledR}$ water was passed across the surface of the buckypapers at high pressure for at least $1 \mathrm{~h}$ in order to achieve a stable permeate flux. In the case of a MWNT/CHT BP prepared from a dispersion containing $0.3 \%(\mathrm{w} / \mathrm{v}) \mathrm{CHT}$, this pressure was 18 bar, whereas it was 10 bar for a buckypaper synthesised from a dispersion containing only $0.2 \%(\mathrm{w} / \mathrm{v})$ CHT. The above procedure was carried out in order to ensure that the membrane was securely seated within the filtration cell, and could withstand the operating conditions of this filtration system. Unless otherwise stated, the cross flow velocity was kept constant at $0.35 \mathrm{~m} \mathrm{~s}^{-1}$ during this time. Once a stable permeate flux had been achieved, the pressure was reduced and the permeate flux of pure water (Milli- $\mathrm{Q}^{\circledR}$ ) at different applied pressures was obtained, to enable the calculation of the water permeability of the BP using the same procedure as for the dead-end filtration experiments.

Prior to performing solute rejection experiments, an aqueous solution containing $16 \mathrm{~g} \mathrm{~L}^{-1}$ of both $\mathrm{NaCl}$ and $\mathrm{MgSO}_{4}$ was added to the Milli- $\mathrm{Q}^{\circledR}$ water in the filtration system, to produce a feed solution in which the final concentration of both metal cations was $2 \mathrm{~g} \mathrm{~L}^{-1}$. The permeate and retentate were circulated back to the feed reservoir throughout salt rejection experiments. The system was operated continuously for $1 \mathrm{~h}$, after which feed and permeate samples were collected for analysis. At each sampling event, $50 \mathrm{~mL}$ of both the feed and permeate solutions were collected simultaneously. An Agilent 710 Inductively Coupled Plasma - Optical Emission Spectrometer was used to determine the concentration of both cations in the feed and permeate solutions. 


\section{Results and discussion}

\subsection{Preparation of MWNT dispersions containing biopolymers}

Formation of dispersions containing MWNTs and different biopolymer dispersants was monitored using absorption spectrophotometry and optical microscopy. It has been established that MWNTs can generally be more readily dispersed in solution than SWNTs [52]. Consequently we pursued formation of MWNT dispersions using solutions containing relatively low concentrations of biopolymers, and prepared by only briefly applying ultrasonic energy. The latter was an important consideration, as the length of sonication must be sufficient to disperse the MWNTs effectively, but it should not be so long as to create defects in the nanotubes, shorten their lengths, or otherwise adversely affects their electronic properties [53-55]. Absorption spectrophotometry is well suited for monitoring the effects of changes in sonication time or sample conditions on the extent of dispersion of CNTs. This is because it is a convenient method for assessing the extent of debundling of nanotubes in dispersions. Bundled CNTs exhibit minimal absorption in the region between 300 and 1000 $\mathrm{nm}[56,57]$. In contrast, absorbance throughout this region of the spectrum grows in response to increases in the amount of CNTs dispersed in solution [58].

Fig. 1 shows a representative series of absorption spectra obtained by sonicating a sample containing MWNTs and LSZ for different periods of time. The absorbance increased in a regular fashion at all wavelengths as the sonication time was increased up to 7 min. During this period the nanotubes were debundled to an increasing extent, resulting in a dispersion containing a greater concentration of MWNTs. Increasing the sonication further to $10 \mathrm{~min}$ or longer resulted in minimal further changes to the absorption spectrum. This indicated that there was little further debundling of the MWNTs, and that a sonication time of 10 min was sufficient to ensure production of an optimised MWNT/LSZ dispersion. 


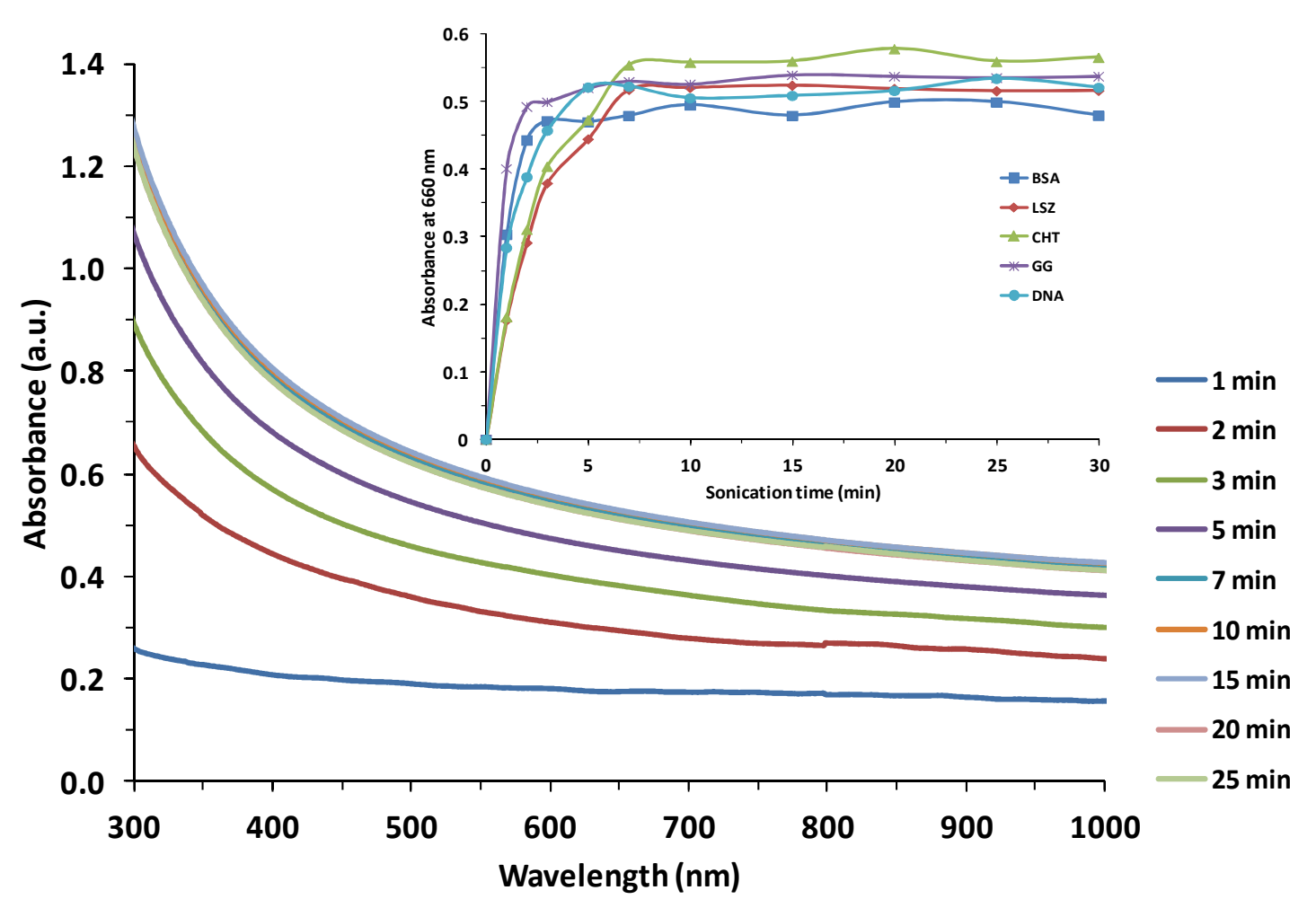

Fig. 1. Effect of increasing sonication time on the absorption spectrum of a typical MWNT/LSZ dispersion. The inset shows the effect of increasing sonication time on the absorbance at $660 \mathrm{~nm}$ of MWNT dispersions containing different biopolymer dispersants. All samples were measured after being diluted 100× using Milli$\mathrm{Q}^{\circledR}$ water (concentration of MWNTs $=0.001 \%(\mathrm{w} / \mathrm{v})$ after dilution).

In order to identify a suitable sonication time for preparing the other types of dispersions, the absorbance at a single wavelength $(660 \mathrm{~nm})$ was monitored as a function of time for samples containing MWNTs and individual biopolymers. This wavelength was chosen as it had been used previously in experiments designed to determine the optimum sonication time for producing dispersions containing SWNTs and biopolymers [46]. The inset in Figure 1 shows how absorbance at $660 \mathrm{~nm}$ varied for each of the MWNT/biopolymer dispersions produced as part of the current work, in response to increasing sonication time. In each case absorbance had either reached or was nearing a plateau region after $10 \mathrm{~min}$ of sonication. This indicates that this period of time was sufficient to produce a highly dispersed sample of MWNTs suitable for preparing buckypapers. Increasing the sonication period resulted in no further significant changes to the absorbance at $660 \mathrm{~nm}$. This contrasts with the behaviour observed 
previously for SWNT dispersions containing many of the same biopolymer dispersants, where absorbance was found to increase significantly with sonication time up to 24 min [46].

The effect of increasing sonication time on the physical appearance of the MWNT/biopolymer dispersions was also examined using optical microscopy. Fig. S4 shows some typical results obtained, using a MWNT/LSZ dispersion as an example. After just 1 min of sonication large clumps of MWNTs can still be clearly seen, however after 10 min the dispersion obtained was homogeneous, with no solid aggregates of non-stabilized carbonaceous material apparent. This provides further evidence that at sonication times $>10$ min the bundles of MWNTs have been completely separated.

\subsection{Surface morphology and composition of BPS}

Fig. 2 shows SEM images of the five MWNT BPs prepared in this study. Each shows a highly entangled mass of nanotubes on the surface of the membranes, and is similar to the morphology reported previously for MWNT/Trix (Trix = Triton X-100) BPs, which were prepared by the same method [34]. Of the five membranes shown in Fig. 2, the MWNT/LSZ BP exhibited the tightest packing of nanotube fibres, and thus, appeared to have a lower proportion of larger pore openings on its surface. Overall, however, the surface morphology of the five MWNT BPs resembled each other very closely. In contrast, SEM studies showed significant differences between the surface morphology of BPs composed of SWNTs and the same biopolymer dispersants [46]. This suggests either that there may have been limited retention of biopolymer molecules in the case of the MWNT BPs, or that they inherently differ very little in surface, and possibly internal morphology. Evidence in support of the latter explanation is provided by reports that BPs prepared from dispersions containing SWNTs and low molecular mass dispersants also exhibited a greater range of surface 
morphologies in SEM studies [33], than the corresponding membranes prepared using the same dispersants and MWNTs [35].

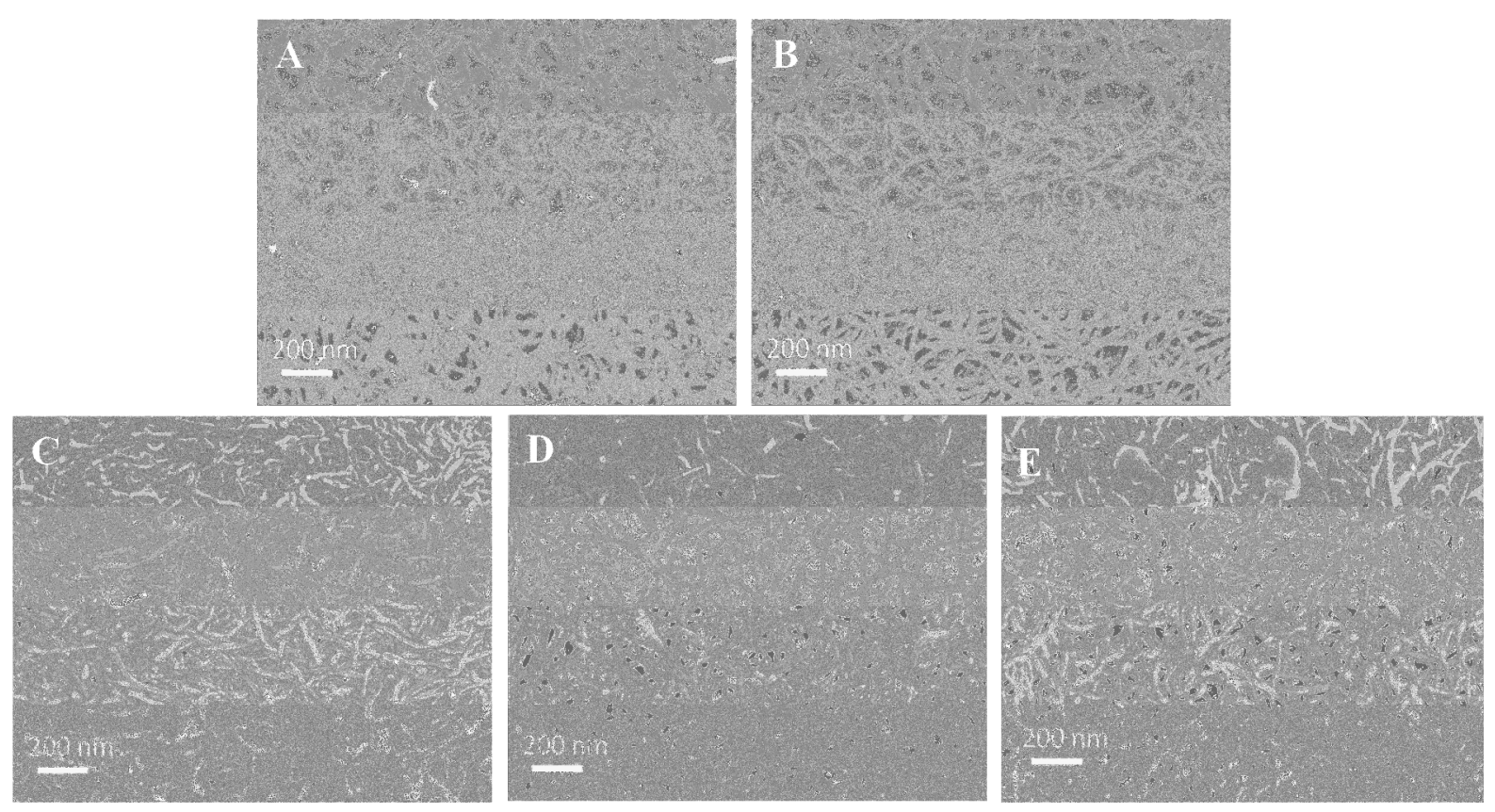

Fig. 2. Scanning electron microscope images of different buckypapers imaged at 70,000× magnification: (A) MWNT/BSA; (B) MWNT/CHT; (C) MWNT/LSZ; (D) MWNT/GG and (E) MWNT/DNA.

Elemental analysis (Table 1) was obtained from each of the BPs to establish whether the biopolymer molecules had been retained within their structures. Both BPs prepared using protein dispersants and, to a lesser extent, that prepared using DNA, showed significantly greater amounts of $\mathrm{N}$ than the pristine MWNTs. This provides support for a significant degree of retention of these biopolymers in the BPs. Further evidence is provided by the observation that $\mathrm{P}$ was incorporated into the MWNT/DNA membrane, and S for both of the materials prepared using protein dispersants. Table 1 also shows that the MWNT/CHT buckypaper contained $1.3 \% \mathrm{~N}$, which is significantly greater than the amount present in the pristine MWNTs $(<0.3 \%)$. This indicates that $\mathrm{N}$ was incorporated into the MWNT/CHT buckypaper, as expected, owing to the presence of amine groups in chitosan. 
The only dispersant used which does not contain $\mathrm{N}, \mathrm{S}$ or $\mathrm{P}$ was gellan gum. Therefore in order to determine if it had been retained in the MWNT/GG buckypapers it was necessary to look closely at the percentages of $\mathrm{C}$ and $\mathrm{H}$ in these membranes. For the MWNT/GG buckypaper, the amount of $\mathrm{H}$ present was greater than for any other membrane, and far in excess of that in the pristine MWNTs. Furthermore the amount of $\mathrm{C}$ present was considerably less than for any of the other BPs. Both of these suggestions are consistent with retention of gellan gum molecules within the MWNT/GG buckypaper.

The percentage composition of elements such as N, S and $\mathrm{P}$ within the current MWNT/biopolymer BPs is similar to that of these elements in membranes prepared using either MWNTs or SWNTs, and low molecular mass dispersants [33,35]. Since these elements are not present in significant amounts in either the raw MWNTs used to prepare the BPs, or the solvent, these results provide strong support for the retention of biopolymer molecules within the BPs. This in turn suggests that the lack of variation in their surface morphologies noted above is most likely an inherent characteristic of membranes prepared using MWNTs.

\section{Table 1}

Elemental composition of (non-dispersed) MWNTs and different MWNT/biopolymer BPs. The error in each case is $\pm 0.1 \%$.

\begin{tabular}{cccccc}
\hline \multirow{7}{*}{ Sample } & \multicolumn{5}{c}{ Elemental Composition (\%) } \\
\cline { 2 - 6 } & $\mathrm{C}$ & $\mathrm{H}$ & $\mathrm{N}$ & $\mathrm{S}$ & $\mathrm{P}$ \\
\cline { 2 - 6 } & 97.8 & $<0.3$ & $<0.3$ & $<0.3$ & $<0.3$ \\
Raw MWNTs & 81.2 & 2.4 & 4.6 & 0.5 & 0.0 \\
MWNT/BSA & 85.3 & 1.7 & 3.7 & 0.5 & 0.0 \\
MWNT/LSZ & 84.8 & 1.4 & 1.3 & 0.0 & 0.0 \\
MWNT/CHT & 61.7 & 3.4 & 0.3 & 0.0 & 0.0 \\
MWNT/GG & 82.9 & 1.1 & 2.2 & 0.0 & 1.2 \\
MWNT/DNA & & & & & \\
\hline
\end{tabular}




\subsection{Physical properties of BPs}

We have previously examined the effect of replacing the low molecular mass dispersant Triton X-100 (Trix), by various biopolymers including several of those studied as part of the current investigation, on the mechanical properties of BPs prepared using SWNTs [46]. It was found that the tensile strength of the materials depended on the molecular mass of the dispersant molecules, perhaps as a result of the larger biopolymers being able to overlap and interact with greater numbers of nanotubes. Even more dramatic was the increase in ductility and toughness of the membranes prepared using GG and CHT, compared to those made using Triton X-100, LSZ or BSA. In view of these results we anticipated that the mechanical properties of the MWNT/biopolymer BPs would also show improvements relative to those made using the same CNTs, and low molecular mass dispersants. Fig. 3 shows representative stress-strain curves obtained for the MWNT/biopolymer BPs, while Table 2 collates the tensile strength, ductility, Young's modulus and toughness derived from those curves, along with other selected physical properties. 


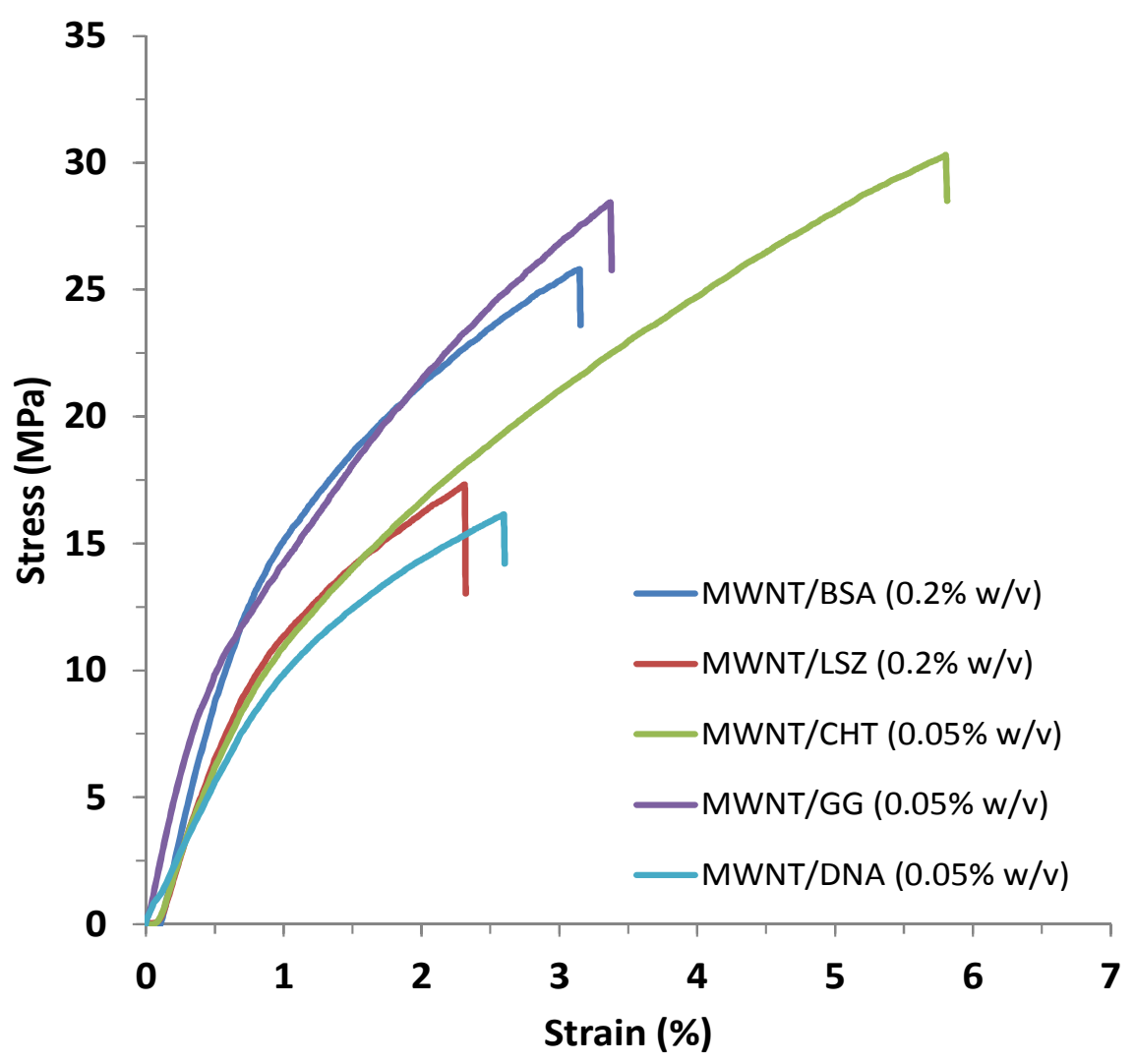

Fig. 3. Representative tensile stress-strain curves for different MWNT buckypapers. The initial concentration of MWNTs in dispersions used to prepare buckypapers was $0.1 \%(\mathrm{w} / \mathrm{v})$.

Inspection of the data in Table 2 reveals some of the same trends observed in our previous study involving SWNT/biopolymer BPs [46]. Most notably, incorporation of the polysaccharide dispersants $\mathrm{CHT}$ and GG again resulted in membranes that exhibited superior ductility and toughness to any of the other materials, including a BP prepared using MWNTs and the low molecular mass dispersant Trix. In addition, the ductility of each of the BPs containing biopolymers was greater than for a range of other membranes prepared using MWNTs and low molecular mass dispersants [35]. It is also apparent from Table 2 that the tensile strength of the MWNT/CHT and MWNT/GG BPs were significantly greater than that of most of the other membranes examined as part of the current study, with the exception of that incorporating BSA. In contrast to the above observations, there was little difference amongst the values derived for the Young's modulus of the materials. In addition, most of 
the MWNT/biopolymer BPs exhibited low electrical conductivities, similar to that reported previously for MWNT/Trix measured using the same technique. Incorporation of the biopolymers in most instances resulted in BPs that were more hydrophilic than MWNT/Trix, according to the results of contact angle analysis.

\section{Table 2}

Physical properties of MWNT/biopolymer buckypapers. All initial dispersions used to prepare buckypapers contained $0.1 \%(\mathrm{w} / \mathrm{v})$ MWNTs. The concentrations of biopolymers in the initial dispersions used for preparing buckypapers were $0.05 \%(\mathrm{w} / \mathrm{v})$ in the case of CHT, GG and DNA, and $0.2 \%(\mathrm{w} / \mathrm{v})$ for LSZ and BSA. Values shown are the average of at least 3 samples, with the errors reported determined from the standard deviation obtained from all measurements.

\begin{tabular}{|c|c|c|c|c|c|c|}
\hline Sample & $\begin{array}{c}\text { Tensile } \\
\text { strength (MPa) }\end{array}$ & Ductility (\%) & $\begin{array}{c}\text { Young's } \\
\text { modulus (GPa) }\end{array}$ & Toughness (J/g) & $\begin{array}{c}\text { Electrical } \\
\text { conductivity }(\mathrm{S} / \mathrm{cm})\end{array}$ & $\begin{array}{l}\text { Contact } \\
\text { angle }\left({ }^{0}\right)\end{array}$ \\
\hline MWNT/Trix ${ }^{a}$ & $6 \pm 3$ & $1.3 \pm 0.2$ & $0.6 \pm 0.3$ & $0.10 \pm 0.06$ & $24 \pm 16$ & $55 \pm 10$ \\
\hline MWNT/BSA & $24 \pm 3$ & $3.2 \pm 1.0$ & $0.7 \pm 0.3$ & $0.4 \pm 0.2$ & $28 \pm 2$ & $57 \pm 6$ \\
\hline MWNT/LSZ & $13 \pm 3$ & $2.9 \pm 1.2$ & $0.5 \pm 0.2$ & $0.2 \pm 0.1$ & $24 \pm 1$ & $32 \pm 3$ \\
\hline MWNT/CHT & $28 \pm 2$ & $5.3 \pm 2.7$ & $0.9 \pm 0.3$ & $1.7 \pm 0.3$ & $48 \pm 5$ & $32 \pm 4$ \\
\hline MWNT/GG & $26 \pm 2$ & $4.0 \pm 0.6$ & $0.6 \pm 0.1$ & $1.7 \pm 0.4$ & $26 \pm 1$ & $39 \pm 5$ \\
\hline MWNT/DNA & $14 \pm 2$ & $2.2 \pm 0.7$ & $0.4 \pm 0.1$ & $0.6 \pm 0.2$ & $30 \pm 2$ & $29 \pm 2$ \\
\hline
\end{tabular}

${ }^{a}$ Data from [35].

The data in Table 2 confirmed our hypothesis that incorporation of the biopolymers into MWNT BPs would result in significant improvements to their mechanical properties, thus making them attractive candidates for water permeability and solute rejection experiments. In addition, the above observations also raised the question of whether further improvements to the mechanical properties could be obtained by preparing the BPs from dispersions containing higher concentrations of the biopolymers. In order to test this hypothesis, MWNT/biopolymer BPs were prepared using four different concentrations of each of the biopolymers, and their mechanical properties measured. The results of this investigation are presented in Figure 4 and Table S1. 
(A)

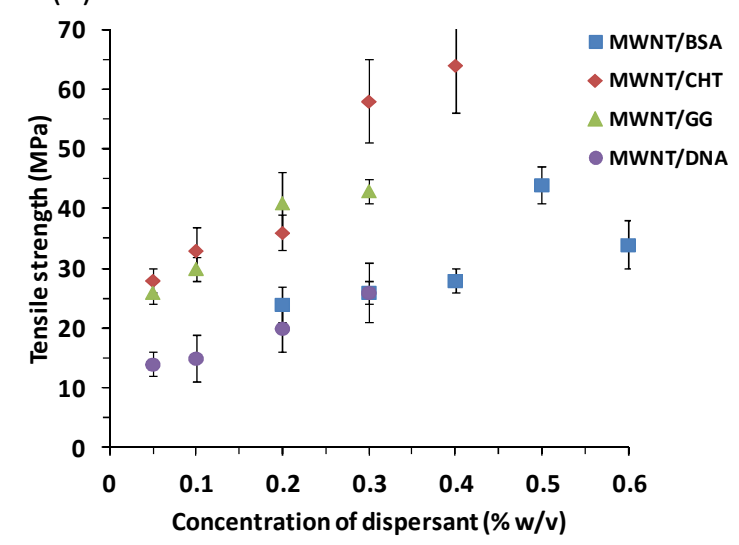

(C)

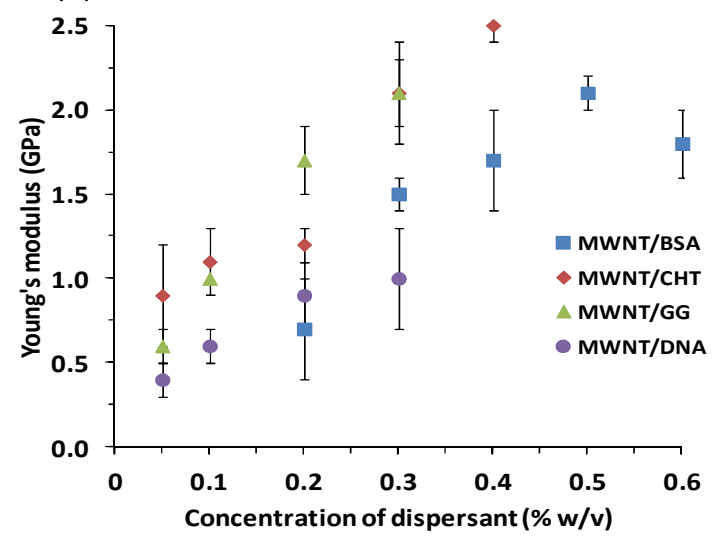

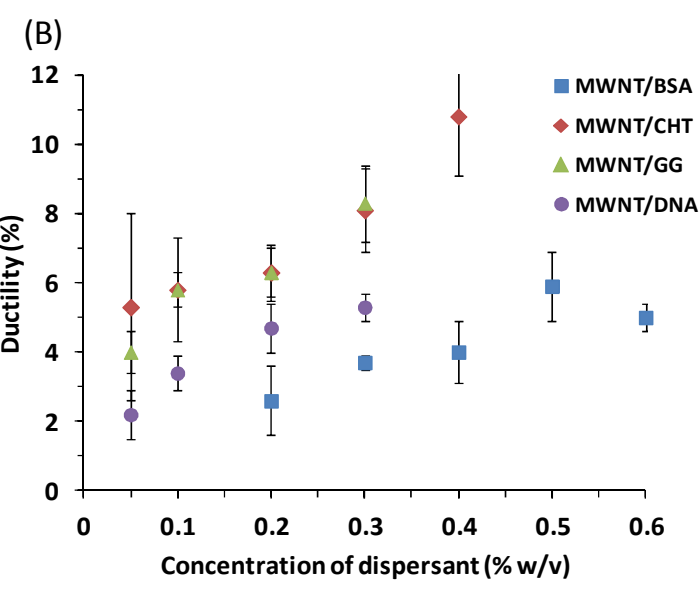

(D)

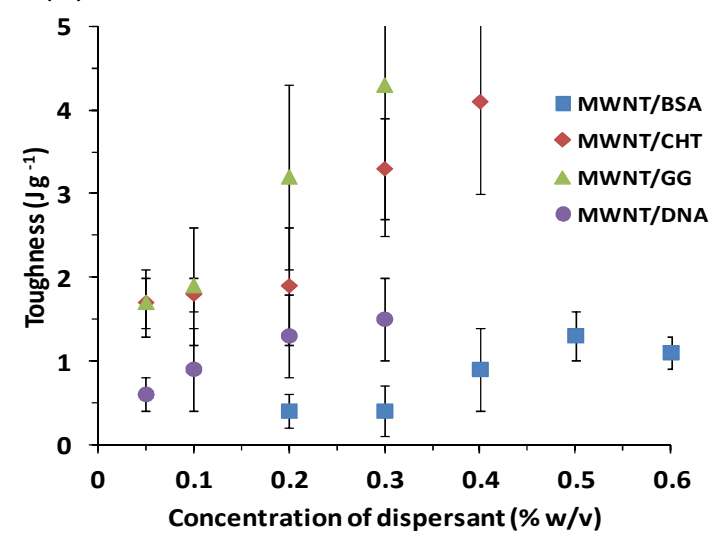

Figure 4. Effect of the initial concentration of biopolymer used during preparation of MWNT/biopolymer dispersions, on the mechanical properties of different buckypapers: (A) tensile strength; (B) ductility; (C) Young's modulus and (D) toughness.

Increasing the concentration of gellan gum or DNA in the solutions used to prepare buckypapers from $0.05 \%$ to $0.3 \%$ (w/v) resulted in significant improvements in all four mechanical properties, as did raising the concentration of chitosan from 0.05 to $0.4 \%(\mathrm{w} / \mathrm{v})$. For example, in the case of MWNT/CHT buckypapers the tensile strength, ductility, Young's modulus and toughness were each found to increase by more than $100 \%$. These results suggest that even more robust BPs could have been prepared using solutions containing even higher concentrations of these dispersants. However, this was not pursued owing to the considerable difficulty associated with filtering the viscous dispersions used to produce the membranes. Furthermore examination of the mechanical properties of MWNT/BSA BPs obtained using solutions containing increasing concentrations of BSA, suggested that for 
some materials there may be an optimum concentration of dispersant, and that use of higher concentrations may result in less robust materials. In the case of MWNT/BSA BPs, all mechanical properties showed significant improvements when the concentration of BSA in the dispersions used to produce the membranes was raised from 0.2 to $0.5 \%(\mathrm{w} / \mathrm{v})$. Further raising the concentration of BSA to $0.6 \%(\mathrm{w} / \mathrm{v})$, however, resulted in small, but noteworthy decreases in the mechanical properties. The results presented in Figure 4 therefore highlight the potential benefits of preparing BPs from solutions containing MWNTs as well as relatively high concentrations of biopolymer dispersant. A drawback associated with such a strategy is that the amount of time required to filter the dispersions to yield the BPs in some instances increases from a few hours to $3-4$ days. As a consequence, the internal morphological properties and permeability characteristics of the membranes were investigated using materials prepared from dispersions containing the lowest concentrations of biopolymer reported in Figure 4.

Nitrogen adsorption/desorption measurements were performed on each of the BPs, resulting in Type IV isotherms such as those presented in Fig. 5 for MWNT/CHT and MWNT/LSZ. Each of the isotherms was similar in overall appearance to those obtained previously for BPs prepared using MWNTs and low molecular weight dispersants [34,35]. For example, the isotherms illustrated in Fig. 5 all exhibit a significant degree of adsorption and desorption at all relative pressures, as well as hysteresis at higher relative pressures. All isotherms were analysed using the Barrett, Joyner and Halenda (BJH) [49], and Horvath-Kawazoe (HK) methods [48], to yield the surface and internal morphological properties compiled in Table 4. In addition, the insets in Fig. 5 shows the distribution of pore sizes for both buckypapers derived through analysis of the isotherms using the BJH approach. 


\section{Table 4}

Surface morphological and internal pore properties of different MWNT buckypapers. All initial dispersions used for preparing buckypapers contained $0.1 \%$ (w/v) MWNTs. These initial dispersions also contained one of the following dispersants:) Trix 1.0\% (w/v); CHT, GG or DNA $0.05 \%$ (w/v), LSZ or BSA 0.2\% (w/v).

\begin{tabular}{|c|c|c|c|c|c|}
\hline Sample & $\begin{array}{l}\text { Average surface pore } \\
\text { diameter } D_{\text {SEM }}(\mathrm{nm})^{*}\end{array}$ & $\begin{array}{l}\text { Specific surface } \\
\text { area } A_{\mathrm{BET}}\left(\mathrm{m}^{2} \mathrm{~g}^{-1}\right)\end{array}$ & $\begin{array}{l}\text { Average internal pore } \\
\text { diameter } d_{\mathrm{BET}}(\mathrm{nm})\end{array}$ & $\begin{array}{c}\text { Average nanotube } \\
\text { bundle diameter } \\
D_{\text {bun }}(\mathrm{nm})\end{array}$ & $\begin{array}{l}\text { Interbundle Pore } \\
\text { volume (\%) }\end{array}$ \\
\hline Raw MWNTs & ------------ & $290 \pm 2$ & $29 \pm 3$ & $9.2 \pm 0.1$ & $96 \pm 3$ \\
\hline MWNT/Trix & $80 \pm 20$ & $251 \pm 2$ & $17 \pm 2$ & $10.6 \pm 0.1$ & $78 \pm 4$ \\
\hline MWNT/BSA & $51 \pm 13$ & $136 \pm 1$ & $19 \pm 1$ & $19.6 \pm 0.2$ & $86 \pm 5$ \\
\hline MWNT/LSZ & $33 \pm 9$ & $161 \pm 1$ & $16 \pm 1$ & $16.5 \pm 0.2$ & $82 \pm 4$ \\
\hline MWNT/CHT & $54 \pm 12$ & $196 \pm 1$ & $23 \pm 3$ & $13.6 \pm 0.2$ & $83 \pm 5$ \\
\hline MWNT/GG & $48 \pm 11$ & $163 \pm 1$ & $20 \pm 2$ & $16.3 \pm 0.2$ & $86 \pm 5$ \\
\hline MWNT/DNA & $52 \pm 10$ & $200 \pm 2$ & $23 \pm 3$ & $13.3 \pm 0.1$ & $83 \pm 5$ \\
\hline
\end{tabular}

* Average surface pore diameter determined by scanning electron microscopy. All other parameters determined through analysis of results obtained from nitrogen adsorption/desorption isotherms.

The average surface pore diameters derived for the MWNT/biopolymer BPs using the Brunnauer, Emmett and Teller (BET) method [50], here were all significantly less than that obtained for MWNT/Trix. This was a somewhat surprising, as SEM suggested that there was little difference between the surfaces of the latter buckypaper on the one hand, and those containing the biopolymers. Furthermore analysis of the isotherms derived from BPs containing MWNTs and low molecular weight dispersants (such as using the BET approach [34,35], gave surface areas similar to that of MWNT/Trix, in contrast to the MWNT/biopolymer membranes reported here. For example, the average surface pore diameters of MWNT/C6S (C6S = 4-sulphonic calix-6-arene), MWNT/PTS (PTS = phthalocyaninetetrasulfonic acid) and MWNT/TSP $(\mathrm{TSP}=\operatorname{meso-tetra}(4-$ sulfonatophenyl)calix-6-arene) buckypapers were $78 \pm 26,69 \pm 21$, and $88 \pm 23 \mathrm{~nm}$, respectively. These values were comparable to the value derived from a MWNT/Trix membrane $(80 \pm 20 \mathrm{~nm})$ [35]. In contrast, the surface areas determined for the BPs containing MWNTs and biopolymers examined as part of the current work, were less than $54 \mathrm{~nm}$. The latter materials were also found to generally have lower surface areas than previously studied 
membranes prepared using lower molecular mass dispersants. All five MWNT/biopolymer BPs had surface areas of less than $200 \mathrm{~m}^{2} \mathrm{~g}^{-1}$, while the majority of those studied previously exhibited surface areas significantly greater than this value [34,35].

The data presented in Table 4 also shows that significant differences exist between the internal pore structures of the MWNT/biopolymer BPs, and those examined previously prepared from the same type of CNTs and low molecular weight dispersants (such as C6S, TSP and PTS). Incorporation of the latter dispersants was found to typically result in buckypapers with average nanotube bundle diameters of less than $11 \mathrm{~nm}[34,35]$. In contrast, all of the membranes investigated as part of the current study exhibited average nanotube bundle diameters of more than $13.0 \pm 0.1 \mathrm{~nm}$. As a consequence, the average internal pore diameters of the latter materials were in a number of instances slightly smaller, resulting in interbundle pore volumes that were less than $86 \%$, whereas those reported previously for the other class of MWNT BPs were more than 90\% [35].

Examination of the surface and internal morphologies of the MWNT BPs containing biopolymers therefore revealed some consistent differences from those of membranes previously examined which contained this class of CNTs. These differences, combined with the contrasting range of intermolecular interactions afforded by the presence of the biopolymers in the latter class of materials, was hoped might lead to novel water and solute permeability characteristics. These properties were therefore explored by performing experiments using two different classes of membrane filtration equipment. 


\subsection{Water, TrOC and salt permeability studies}

All five BPs show a linear correlation between permeate flux and applied pressure (Fig. 6), thus, allowing for the determination of the permeability value. It is evidenced that the obtained permeability values are dependent on both the thickness and pore size of the membrane. For example, the MWNT/CHT BP has the highest water permeability corresponding to the smallest thickness (Table 5). However, it is noteworthy that a linear correlation between water permeability and membrane thickness could not be conclusively obtained.

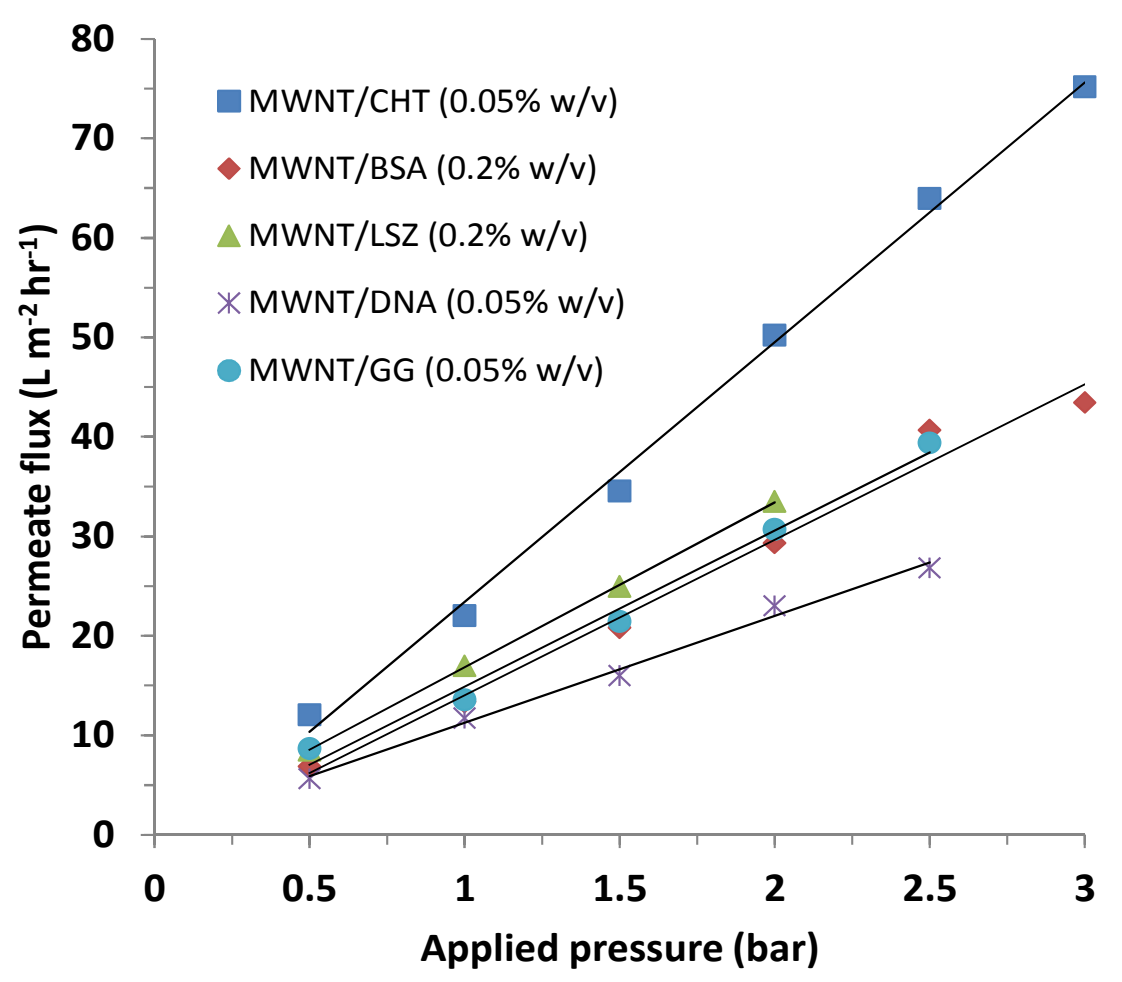

Fig. 6. Effect of applied pressure on the permeate flux $(J)$ of MWNT/biopolymer buckypapers. All dispersions contained MWNTs with a concentration of $0.1 \%(\mathrm{w} / \mathrm{v})$.

The five MWNT/biopolymer BPs in this study have similar thickness to membrane previously prepared using MWNTs and low molecular weight dispersants (such as C6S, TSP and PTS). Thus, their liquid entry pressures (i.e. the smallest applied pressure required for 
water transport) were also similar, in the range from 0.25 to 0.6 bar. In the case of the MWNT/LSZ BP, this pressure was $0.60 \pm 0.15$ bar, while for other BPs prepared using MWNTs or substituted MWNTs, and low molecular weight dispersants (such as C6S, TSP and PTS), the initiating pressure was 0.51 bar or less [35]. Of a particular note, the MWNT BPs prepared with biopolymers in this study had significantly higher rupture pressures than and those with low molecular weight dispersants (such as C6S, TSP and PTS) previously reported in the literature. All BPs in this study showed a rupture pressure of more than 2.0 bar. The MWNT/CHT and MWNT/BSA BPs were especially robust (rupture pressure of 3.7 \pm 0.2 and $3.4 \pm 0.1$ bar, respectively). In contrast, the rupture pressure of MWNT BPs prepared from low molecular weight dispersants (such as C6S, TSP and PTS) previously reported in the literature was much lower (less than 1.4 bar) [35]. Membranes composed of SWNTs, but containing the same low molecular weight dispersants, have also been shown to be susceptible to failure, with membrane rupture pressures of less than1.4 bar [33]. These observations are consistent with the improved mechanical properties of the biopolymercontaining membranes (section 3.3).

Table 5

Membrane permeability $(f)$, water transport initiation pressure, rupture pressure and thickness of MWNT/biopolymer buckypapers. * All initial dispersions used for preparing buckypapers contained $0.1 \%$ (w/v) MWNTs.

\begin{tabular}{llllll}
\hline Sample & $\begin{array}{l}\text { Initial } \\
\text { concentration } \\
\text { of dispersant } \\
(\% \mathrm{w} / \mathrm{v})\end{array}$ & $\begin{array}{l}\text { Membrane } \\
\text { permeability }(f) \\
\left(\mathrm{L} \mathrm{m}^{-2} \mathrm{~h}^{-1} \text { bar }^{-1}\right)\end{array}$ & $\begin{array}{l}\text { Liquid entry } \\
\text { pressure }(\text { bar })\end{array}$ & $\begin{array}{l}\text { Rupture } \\
\text { pressure }(\text { bar })\end{array}$ & $\begin{array}{l}\text { Thickness } \\
(\mu \mathrm{m})\end{array}$ \\
\hline MWNT/BSA & 0.2 & $10 \pm 4$ & $0.40 \pm 0.10$ & $3.4 \pm 0.1$ & $59 \pm 7$ \\
MWNT/LSZ & 0.2 & $14 \pm 3$ & $0.60 \pm 0.15$ & $2.7 \pm 0.3$ & $58 \pm 3$ \\
MWNT/CHT & 0.05 & $22 \pm 4$ & $0.30 \pm 0.05$ & $3.7 \pm 0.2$ & $41 \pm 3$ \\
MWNT/GG & 0.05 & $19 \pm 3$ & $0.25 \pm 0.05$ & $2.0 \pm 0.6$ & $63 \pm 5$ \\
MWNT/DNA & 0.05 & $13 \pm 2$ & $0.50 \pm 0.15$ & $2.5 \pm 0.5$ & $44 \pm 4$ \\
\hline
\end{tabular}

* Values shown are the average and standard deviation from measurements made on at least three samples. 
Water permeabilities of the five MWNT/biopolymer BPs were in the range from 10 to $22 \mathrm{~L}$ $\mathrm{m}^{-2} \mathrm{~h}^{-1}$ bar $^{-1}$. These values are comparable to those from BPs composed of MWNTs and low molecular mass dispersants (such as C6S, TSP, PTS) (from $17 \pm 4$ to $24 \pm 6 \mathrm{~L} \mathrm{~m}^{-2} \mathrm{~h}^{-1} \mathrm{bar}^{-1}$ ) [35]. Thus, by incorporating biopolymers into MWNT BPs, a marked improvement in mechanical properties can be achieved without compromising the water permeability. In particular, the MWNT/CHT BP is the most suitable for further investigation, as their rupture pressure and membrane flux were both superior to that of the others investigated here.

A series of experiments was conducted to determine the effects of biopolymers in MWNT BPs on their permeability towards a mixture of twelve small molecular weight $\left(<400 \mathrm{~g} \mathrm{~mol}^{-}\right.$ ${ }^{1}$ ) TrOCs. The organic molecules chosen for examination included pharmaceuticals, personal care products and pesticides. These TrOCs included neutral compounds and with a range of net charges at neutral $\mathrm{pH}$. The experimental protocol was described in section 2.5. The MWNT/GG BP was excluded from this experiment due to its low rupture pressure. Fig. 7 shows the final percentage removals obtained at the end of the experiments. The removal of each TrOC as a function of permeate volume is shown in the Supplementary Data Fig. S4. 
(A)
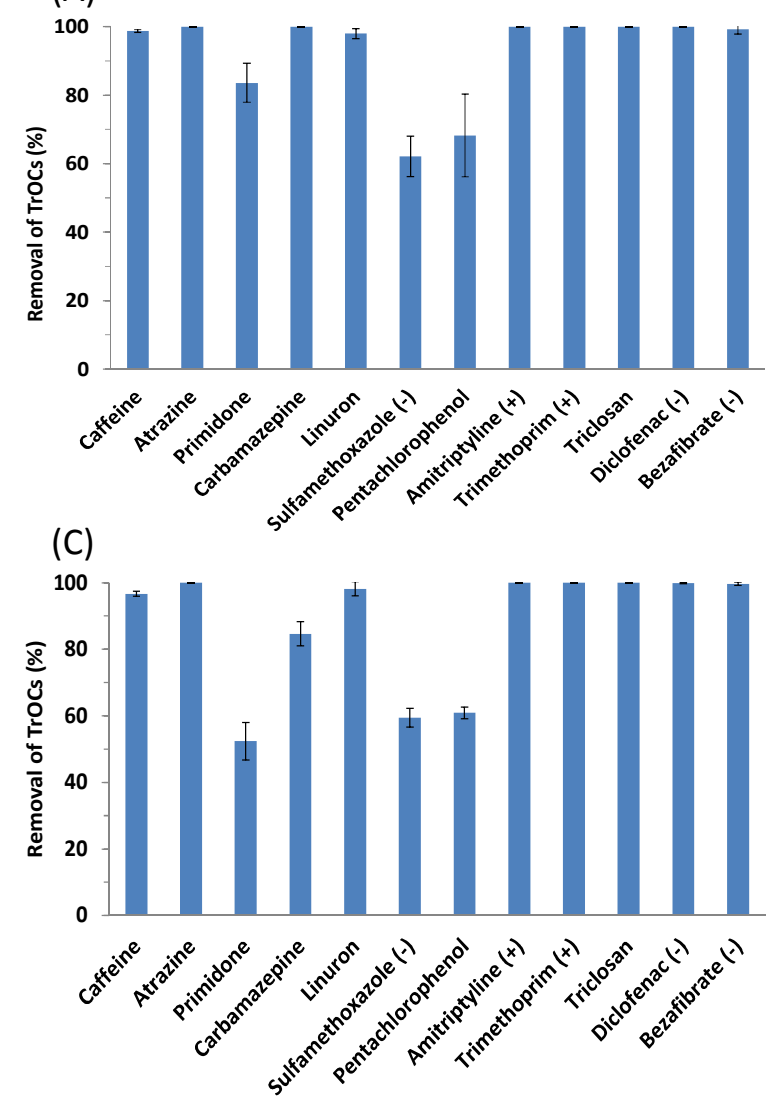

(B)
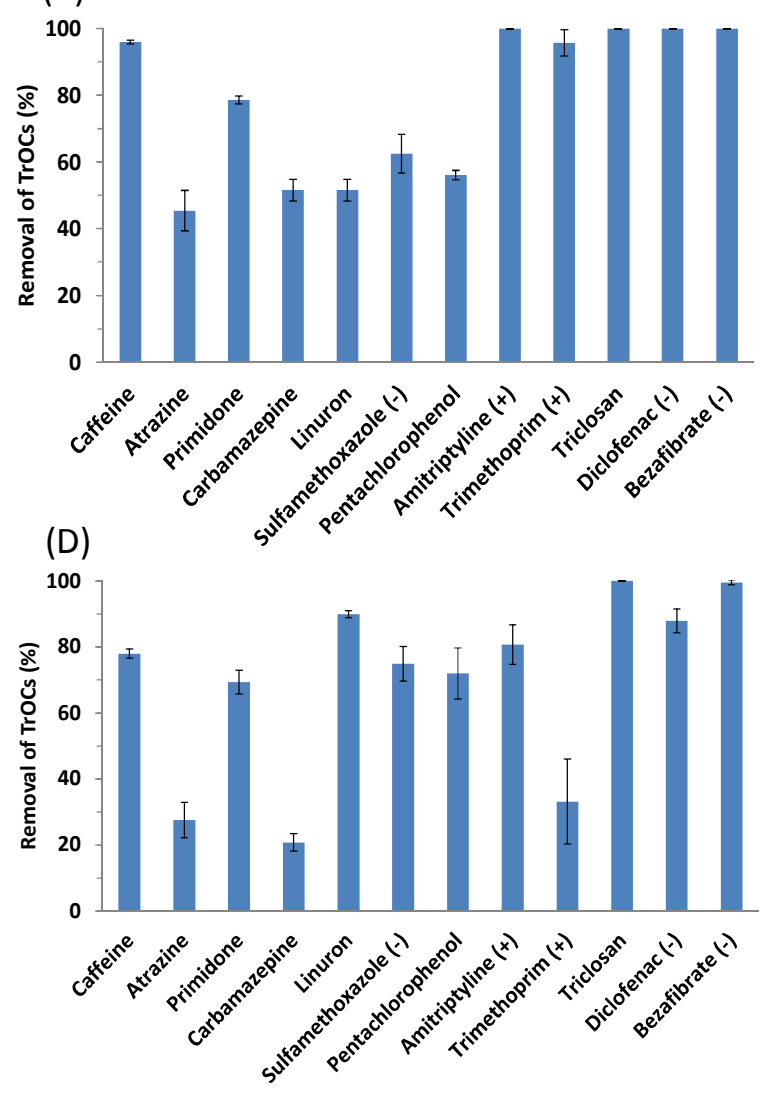

Fig. 7. Final percentage removal of different TrOCs by buckypapers: (A) MWNT/CHT; (B) MWNT/BSA; (C) MWNT/DNA and (D) MWNT/LSZ. All initial dispersions used for preparing buckypapers contained $0.1 \%$ (w/v) MWNTs. The concentrations of biopolymers in the initial dispersions were $0.05 \%(w / v)$ in the case of CHT, GG and DNA, and $0.2 \%(\mathrm{w} / \mathrm{v})$ for LSZ and BSA. (Organic compounds are listed here in the increasing order of molecular weight).

The permeability of the BPs towards the mixture of twelve TrOCs varied significantly. The MWNT/CHT BP achieved the highest TrOC removal and the removal value for nine of the twelve TrOCs was over 95\%. In contrast, the MWNT/LSZ BP could only achieve over 95\% removal for two TrOCs. The MWNT/LSZ BP also exhibited low removals of less than $40 \%$ of three TrOCs (trimethoprim, carbamazepine and atrazine), while no other BPs exhibited such a low removal value of all twelve TrOCs investigated here. These results suggest that pore sizes of these BPs may differ markedly from one another. The results are in good agreement with our suggestion above that water permeability of these BPs are a function of both membrane thickness and pore size. 
Overall, the permeability towards the mixture of TrOCs was in the following order: MWNT/CHT < MWNT/DNA MWNT/BSA < MWNT/LSZ. The two BPs containing protein dispersants (i.e. BSA and LSZ) were the most permeable towards TrOCs. This may be rationalised by proposing that the greater range of functional groups present in these biopolymers (e.g. carboxylic acid, hydroxyl, thiol, phenol, guanidine, amine) may have facilitated interactions that lead to the transport of the organic compounds across the BPs. In contrast, chitosan only contains hydroxyl and amine groups, and DNA a range of aromatic nitrogen and amine nitrogen atoms, as well as phosphates and hydroxyls. This may have limited the range of interactions that can take place, particularly with TrOCs bearing hydrophilic groups, which would draw the organic compounds to the surface of the membrane, and then facilitate their transfer through the intermolecular pores. In a good agreement with this hypothesis, MWNT/Trix membranes were previously shown to exhibit a much higher rejection of these TrOCs compared to MWNT/PTS membranes [35]. Ether oxygen of the Trix dispersant was the only functional groups present in the MWNT/Trix membranes, whereas PTS contains both imine and sulfonic acid groups.

Nanofiltration and desalination of water samples are currently amongst the most important applications of membrane technology. There have not been any attempts to examine the desalination ability of free-standing BPs via nanofiltration. In this study, MWNT/CHT membranes were prepared containing higher dispersant concentration of 0.2 and $0.3 \%(\mathrm{w} / \mathrm{v})$ to achieve a high rupture pressure necessary for nanofiltration application. It is noted that the MWNT/CHT showed the best mechanical properties and the highest rupture pressure amongst all five membranes investigated in this study (section 3.3). In addition, the filtration step to produce MWNT/CHT membranes was significantly shorter than for other BPs. 
Fig. 8 presents the results of these experiments. From the slopes of the two graphs, the membrane flux of the MWNT/CHT $\left(0.2 \%(\mathrm{w} / \mathrm{v})\right.$ BP was determined to be $29 \pm 6 \mathrm{~L} \mathrm{~m}^{-2} \mathrm{~h}^{-1}$ $\mathrm{bar}^{-1}$, while for the MWNT/CHT $(0.3 \%(\mathrm{w} / \mathrm{v})$ membrane it was significantly lower $(11 \pm 1 \mathrm{~L}$ $\mathrm{m}^{-2} \mathrm{~h}^{-1}$ bar $^{-1}$ ). These results show that there is therefore a trade off between the greater mechanical strength afforded by the presence of additional dispersant molecules, and outright permeability. It is noteworthy that the permeability of the BP prepared from a solution containing $0.2 \%(\mathrm{w} / \mathrm{v})$ was higher in experiments performed using the cross-flow than when using the dead-end filtration cell.

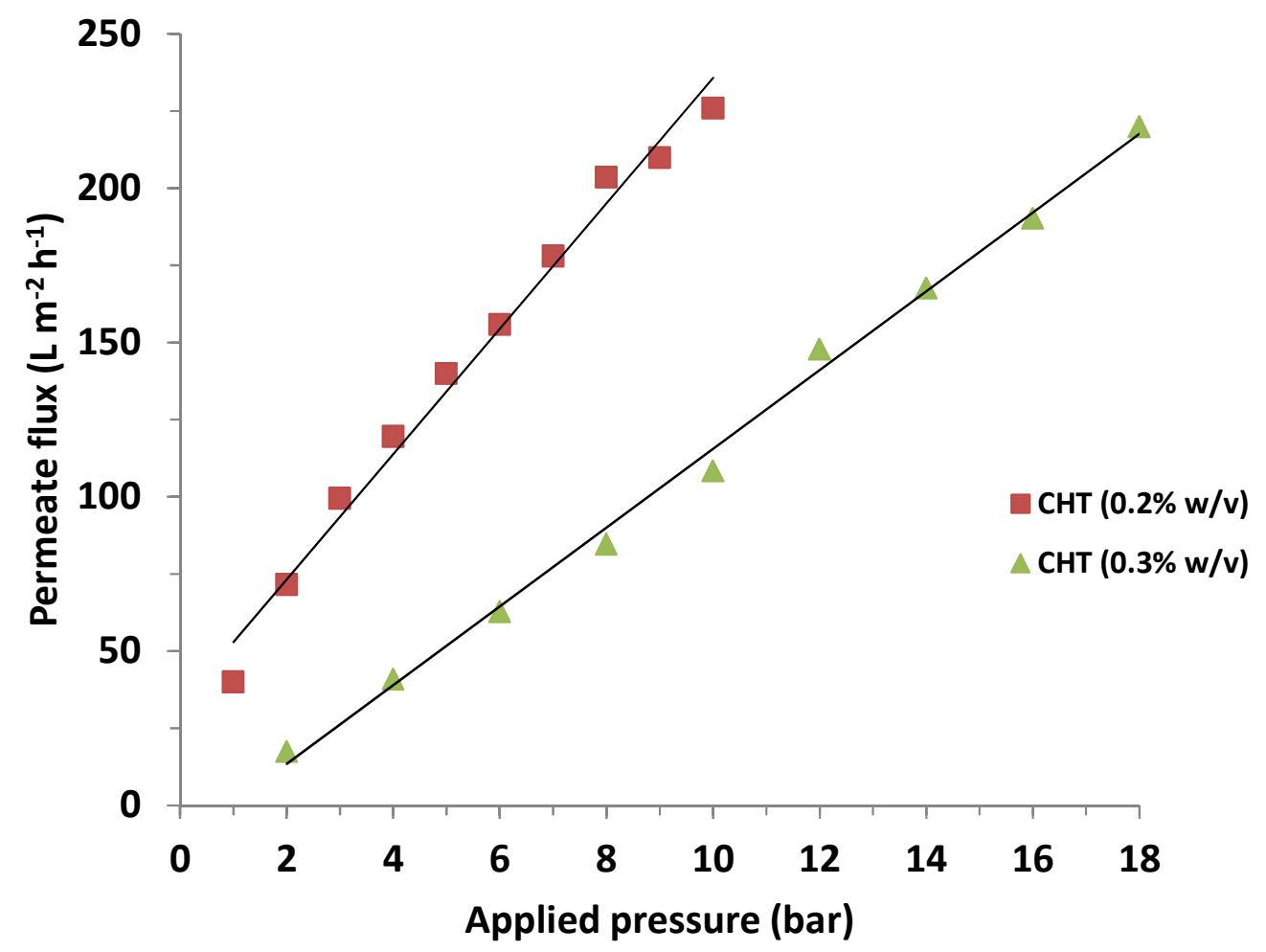

Fig. 8. Effect of applied pressure on the permeate flux $(J)$ of different MWNT/CHT free-standing buckypapers operating in a cross flow NF/RO filtration system. Solid lines are linear fit to the data. All buckypapers were prepared from initial dispersions containing $0.1 \%(w / v)$ MWNTs. A schematic illustration of the filtration system can be found in Fig. S3.

The same two types of BPs were then used in solute rejection experiments performed using a feed solution containing the same mixture of twelve TrOCs, as well as $2 \mathrm{~g} \mathrm{~L}^{-1} \mathrm{NaCl}$ and 
$\mathrm{MgSO}_{4}$. Fig. 9 shows how the effect of applied pressure on the extent of rejection of $\mathrm{NaCl}$ and $\mathrm{MgSO}_{4}$, by both BPs. In the case of the BP prepared from a solution containing MWNTs and $0.2 \%(\mathrm{w} / \mathrm{v})$ chitosan, the extent of salt rejection could be monitored until the applied pressure reached $c a$. 10 bar, at which point membrane rupture occurred. In contrast, membrane rupture did not occur until an applied pressure of ca. 18 bar was reached for the BP prepared from a dispersion of MWNTs and $0.3 \%(\mathrm{w} / \mathrm{v})$ chitosan, reflecting greater mechanical integrity of this membrane.

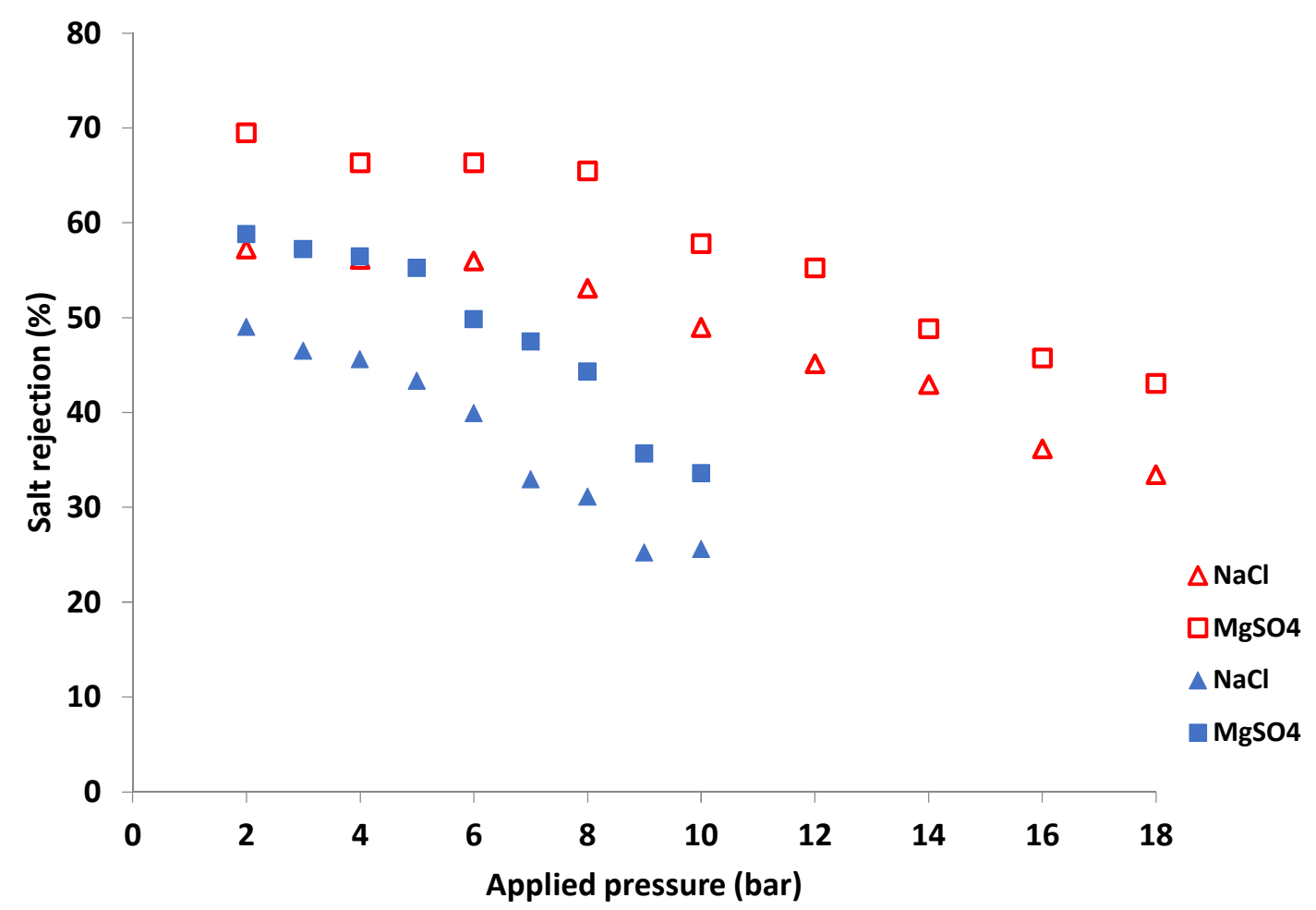

Fig. 9. Effect of applied pressure on the extent of salt rejection by MWNT/CHT BPs prepared from initial dispersions containing $0.1 \%(\mathrm{w} / \mathrm{v})$ MWNTs and either $0.2 \%(\mathrm{w} / \mathrm{v}) \mathrm{CHT}$ (closed symbols) or $0.3 \%(\mathrm{w} / \mathrm{v}) \mathrm{CHT}$ (open symbols).

With both types of BPs the extent of rejection of $\mathrm{NaCl}$ and $\mathrm{MgSO}_{4}$ was found to decrease significantly as the applied pressure was raised. In addition, the extent of rejection of $\mathrm{MgSO}_{4}$ was found to be slightly greater than that of $\mathrm{NaCl}$ in both instances. This is due to stronger electrostatic interactions between the divalent cations and anions with polar groups on the 
surfaces of the BPs, or a consequence of the greater difficulty with which the larger sulfate anions can traverse the internal pore structures of the two membranes. Fig. 9 also shows that the salt rejection capability of the BP prepared from the solution containing more chitosan was greater at all applied pressures. This may be because this membrane contained more polar and charged groups able to interact with and retard the progress of the charged electrolytes.

\section{Conclusions}

Fabrication of BPs from dispersions prepared using MWNTs and biopolymers resulted in membranes that were mechanically more robust than those reported previously, which had been prepared using dispersants of much lower molecular mass. This effect had been noted previously with analogous materials prepared using dispersions containing SWNTs, and can be attributed to the greater effectiveness with which the larger biopolymer molecules can adsorb onto the surfaces of the nanotubes and thereby bind them together. Increasing the concentration of biopolymer in the dispersion used to fabricate the BPs typically resulted in significant improvements to their mechanical properties. Furthermore the presence of the biopolymers also resulted in a significantly different internal pore structure for the MWNT/biopolymer membranes, compared to those composed of the same type of nanotubes and low molecular mass dispersants. Perhaps the most important point of contrast was the larger nanotube bundle diameters for the former membranes revealed by analysis of the results of nitrogen adsorption/desorption measurements. The presence of significantly larger clumps of nanotubes within the internal structure of the BPs is likely to have been a major contributor to their larger internal pores. Furthermore their effects are likely to have also been 
felt at the surface of the BPs, where the materials prepared using biopolymer dispersants exhibited lower surface areas and surface pore diameters.

The results presented here further demonstrate that incorporation of biopolymer dispersants strengthens BPs, thereby making them potentially viable for water filtration and solute separation applications. Whilst permeability experiments performed using MWNT/biopolymer BPs showed that they did not allow the passage of water molecules as readily as MWNT membranes containing low molecular mass dispersants, they still exhibited a notable ability to reject a variety of dissolved organic solutes. Furthermore we demonstrated for the first time that these materials are capable of rejecting the passage of inorganic solutes. Comparison of the results presented here for MWNT/biopolymer BPs, with those obtained previously composed of MWNTs and low molecular mass dispersants, indicates that the permeability and solute rejection properties of the latter materials are largely retained by the new class of BPs reported here. In future work we intend to explore whether these properties are also exhibited by BPs produced using SWNTs and biopolymer dispersants, and if the greater permeability previously noted for membranes composed of this class of CNTs, are retained in the presence of these high molecular mass dispersants.

\section{References}

[1] Y. Luo, W. Guo, H.H. Ngo, L.D. Nghiem, F.I. Hai, J. Zhang, S. Liang, X.C. Wang, A review on the occurrence of micropollutants in the aquatic environment and their fate and removal during wastewater treatment, Sci. Total Environ. 473-474 (2014) 619641. 
[2] P.D. Scott, M. Bartkow, S.J. Blockwell, H.M. Coleman, S.J. Khan, R. Lim, J.A. McDonald, H. Nice, D. Nugegoda, V. Pettigrove, L.A. Tremblay, M.S.J. Warne, F.D.L. Leusch, An assessment of endocrine activity in australian rivers using chemical and in vitro analyses, Environ. Sci. Pollut. R. 21 (2014) 12951-12967.

[3] W. Brack, S. Ait-Aissa, R.M. Burgess, W. Busch, N. Creusot, C. Di Paolo, B.I. Escher, L. Mark Hewitt, K. Hilscherova, J. Hollender, H. Hollert, W. Jonker, J. Kool, M. Lamoree, M. Muschket, S. Neumann, P. Rostkowski, C. Ruttkies, J. Schollee, E.L. Schymanski, T. Schulze, T.-B. Seiler, A.J. Tindall, G. De Aragão Umbuzeiro, B. Vrana, M. Krauss, Effect-directed analysis supporting monitoring of aquatic environments — an in-depth overview, Sci. Total Environ. 544 (2016) 1073-1118.

[4] T. Ternes, A. Joss, J. Oehlmann, Occurrence, fate, removal and assessment of emerging contaminants in water in the water cycle (from wastewater to drinking water), Water Res. 72 (2015) 1-2.

[5] K. Kimura, G. Amy, J.E. Drewes, T. Heberer, T.-U. Kim, Y. Watanabe, Rejection of organic micropollutants (disinfection by-products, endocrine disrupting compounds, and pharmaceutically active compounds) by NF/RO membranes, J. Membr. Sci. 227 (2003) 113-121.

[6] A.M. Comerton, R.C. Andrews, D.M. Bagley, C. Hao, The rejection of endocrine disrupting and pharmaceutically active compounds by NF and RO membranes as a function of compound and water matrix properties, J. Membr. Sci. 313 (2008) 323335.

[7] K. Kimura, G. Amy, J. Drewes, Y. Watanabe, Adsorption of hydrophobic compounds onto NF/RO membranes: An artifact leading to overestimation of rejection, J. Membr. Sci. 221 (2003) 89-101. 
[8] T. Fujioka, S.J. Khan, J.A. McDonald, L.D. Nghiem, Rejection of trace organic chemicals by a nanofiltration membrane: The role of molecular properties and effects of caustic cleaning, Environ. Sci.: Water Res. Technol. 1 (2015) 846-854.

[9] F. Reverberi, A. Gorenflo, Three year operational experience of a spiral-wound SWRO system with a high fouling potential feed water, Desalination 203 (2007) 100106.

[10] T. Tran, B. Bolto, S. Gray, M. Hoang, E. Ostarcevic, An autopsy study of a fouled reverse osmosis membrane element used in a brackish water treatment plant, Water Res. 41 (2007) 3915-3923.

[11] L.N. Nguyen, F.I. Hai, J. Kang, W.E. Price, L.D. Nghiem, Removal of trace organic contaminants by a membrane bioreactor-granular activated carbon, Bioresource Technol. 113 (2012) 169.

[12] D.P. Grover, J.L. Zhou, P.E. Frickers, J.W. Readman, Improved removal of estrogenic and pharmaceutical compounds in sewage effluent by full scale granular activated carbon: Impact on receiving river water, J. Hazard. Mater. 185 (2011) 10051011.

[13] L. Hernández-Leal, H. Temmink, G. Zeeman, C.J.N. Buisman, Removal of micropollutants from aerobically treated grey water via ozone and activated carbon, Water Res. 45 (2011) 2887-2896.

[14] Z. Yu, S. Peldszus, P.M. Huck, Adsorption characteristics of selected pharmaceuticals and an endocrine disrupting compound-naproxen, carbamazepine and nonylphenol—on activated carbon, Water Res. 42 (2008) 2873-2882.

[15] S.A. Snyder, S. Adham, A.M. Redding, F.S. Cannon, J. DeCarolis, J. Oppenheimer, E.C. Wert, Y. Yoon, Role of membranes and activated carbon in the removal of endocrine disruptors and pharmaceuticals, Desalination 202 (2007) 156-181. 
[16] R.H. Baughman, A.A. Zakhidov, W.A. de Heer, Carbon nanotubes--the route toward applications, Science 297 (2002) 787-792.

[17] M.A.L. Manchado, L. Valentini, J. Biagiotti, J.M. Kenny, Thermal and mechanical properties of single-walled carbon nanotubes-polypropylene composites prepared by melt processing, Carbon 43 (2005) 1499-1505.

[18] G.M. Spinks, V. Mottaghitalab, M. Bahrami-Samani, P.G. Whitten, G.G. Wallace, Carbon-nanotube-reinforced polyaniline fibers for high-strength artificial muscles, Adv. Mater. 18 (2006) 637-640.

[19] J.K. Holt, H.G. Park, Y. Wang, M. Stadermann, A.B. Artyukhin, C.P. Grigoropoulos, A. Noy, O. Bakajin, Fast mass transport through sub-2-nanometer carbon nanotubes, Science 312 (2006) 1034-1037.

[20] A. Srivastava, O.N. Srivastava, S. Talapatra, R. Vajtai, P.M. Ajayan, Carbon nanotube filters, Nat. Mater. 3 (2004) 610-614.

[21] B.J. Hinds, N. Chopra, T. Rantell, R. Andrews, V. Gavalas, L.G. Bachas, Aligned multiwalled carbon nanotube membranes, Science 303 (2004) 62-65.

[22] M. Majumder, A. Stinchcomb, B.J. Hinds, Towards mimicking natural protein channels with aligned carbon nanotube membranes for active drug delivery, Life Sci. 86 (2010) 563-568.

[23] R.H. Baughman, A.G. Rinzler, O. Jaschinski, S. Roth, M. Kertesz, C. Cui, A.A. Zakhidov, Z. Iqbal, J.N. Barisci, G.M. Spinks, G.G. Wallace, A. Mazzoldi, D. De Rossi, Carbon nanotube actuators, Science 284 (1999) 1340-1344.

[24] Z. Špitalský, C. Galiotis, C. Aggelopoulos, G. Tsoukleri, C. Tsakiroglou, J. Parthenios, S. Georga, C. Krontiras, D. Tasis, K. Papagelis, The effect of oxidation treatment on the properties of multi-walled carbon nanotube thin films, mater. Sci. Eng. B 165 (2009) 135-138. 
[25] C.J. Frizzell, M. in het Panhuis, D.H. Coutinho, K.J. Balkus, A.I. Minett, W.J. Blau, J.N. Coleman, Reinforcement of macroscopic carbon nanotube structures by polymer intercalation: The role of polymer molecular weight and chain conformation, Phys. Rev. B 72 (2005)

[26] A.S. Brady-Estévez, S. Kang, M. Elimelech, A single-walled-carbon-nanotube filter for removal of viral and bacterial pathogens, Small 4 (2008) 481-484.

[27] A.S. Brady-Estévez, M.H. Schnoor, S. Kang, M. Elimelech, SWNT-MWNT hybrid filter attains high viral removal and bacterial inactivation, Langmuir 26 (2010) 1915319158.

[28] S. Kang, M. Pinault, L.D. Pfefferle, M. Elimelech, Single-walled carbon nanotubes exhibit strong antimicrobial activity, Langmuir 23 (2007) 8670-8673.

[29] S. Kang, M. Herzberg, D.F. Rodrigues, M. Elimelech, Antibacterial effects of carbon nanotubes: Size does matter!, Langmuir 24 (2008) 6409-6413.

[30] E. Celik, L. Liu, H. Choi, Protein fouling behavior of carbon nanotube/polyethersulfone composite membranes during water filtration, Water Res. 45 (2011) 5287-5294.

[31] L. Bai, H. Liang, J. Crittenden, F. Qu, A. Ding, J. Ma, X. Du, S. Guo, G. Li, Surface modification of uf membranes with functionalized mwents to control membrane fouling by nom fractions, J. Membr. Sci. 492 (2015) 400-411.

[32] L.F. Dumée, K. Sears, J. Schütz, N. Finn, C. Huynh, S. Hawkins, M. Duke, S. Gray, Characterization and evaluation of carbon nanotube bucky-paper membranes for direct contact membrane distillation, J. Membr. Sci. 351 (2010) 36-43.

[33] L.J. Sweetman, L. Nghiem, I. Chironi, G. Triani, M. In Het Panhuis, S.F. Ralph, Synthesis, properties and water permeability of SWNT buckypapers, J. Mater. Chem. 22 (2012) 13800-13810. 
[34] L.J. Sweetman, L.J. Alcock, J.D. McArthur, E. Stewart, G. Triani, M. in het Panhuis, S.F. Ralph, Bacterial filtration using carbon nanotube/antibiotic buckypaper membranes, J. Nanomater. (2013) 1-11.

[35] M.H.O. Rashid, S.Q.T. Pham, L.J. Sweetman, L.J. Alcock, A. Wise, L.D. Nghiem, G. Triani, M.I.H. Panhuis, S.F. Ralph, Synthesis, properties, water and solute permeability of mwnt buckypapers, J. Membr. Sci. 456 (2014) 175-184.

[36] X.S. Yang, J. Lee, L.X. Yuan, S.R. Chae, V.K. Peterson, A.I. Minett, Y.B. Yin, A.T. Harris, Removal of natural organic matter in water using functionalised carbon nanotube buckypaper, Carbon 59 (2013) 160-166.

[37] X. Yang, J. Lee, L. Yuan, S.-R. Chae, V.K. Peterson, A.I. Minett, Y. Yin, A.T. Harris, Removal of natural organic matter in water using functionalised carbon nanotube buckypaper, Carbon 59 (2013) 160-166.

[38] D. Lin, B. Xingt, Adsorption of phenolic compounds by carbon nanotubes: Role of aromaticity and substitution of hydroxyl groups, Environ. Sci. Technol. 42 (2008) 7254-7259.

[39] Y.-H. Li, Z. Di, J. Ding, D. Wu, Z. Luan, Y. Zhu, Adsorption thermodynamic, kinetic and desorption studies of $\mathrm{Pb}^{2+}$ on carbon nanotubes, Water Res. 39 (2005) 605-609.

[40] H. Hyung, J.-H. Kim, Natural organic matter (NOM) adsorption to multi-walled carbon nanotubes: Effect of nom characteristics and water quality parameters, Environ. Sci. Technol. 42 (2008) 4416-4421.

[41] G.-C. Chen, X.-Q. Shan, Y.-S. Wang, B. Wen, Z.-G. Pei, Y.-N. Xie, T. Liu, J.J. Pignatello, Adsorption of 2,4,6-trichlorophenol by multi-walled carbon nanotubes as affected by Cu(ii), Water Res. 43 (2009) 2409-2418.

[42] M.S. Mauter, M. Elimelech, Environmental applications of carbon-based nanomaterials, Environ. Sci. Technol. 42 (2008) 5843-5859. 
[43] B. Pan, B. Xing, Adsorption mechanisms of organic chemicals on carbon nanotubes, Environ. Sci. Technol. 42 (2008) 9005-9013.

[44] C.J. Frizzell, M. in het Panhuis, D.H. Coutinho, K.J. Balkus, A.I. Minett, W.J. Blau, J.N. Coleman, Reinforcement of macroscopic carbon nanotube structures by polymer intercalation: The role of polymer molecular weight and chain conformation, Phys. Rev. B 72 (2005) 245420.

[45] J.N. Coleman, W.J. Blau, A.B. Dalton, E. Muñoz, S. Collins, B.G. Kim, J. Razal, M. Selvidge, G. Vieiro, R.H. Baughman, Improving the mechanical properties of singlewalled carbon nanotube sheets by intercalation of polymeric adhesives, Appl. Phys. Lett. 82 (2003) 1682-1684.

[46] J. Boge, L.J. Sweetman, M. In Het Panhuis, S.F. Ralph, The effect of preparation conditions and biopolymer dispersants on the properties of SWNT buckypapers, J. Mater. Chem. 19 (2009) 9131-9140.

[47] F.M. Blighe, Y.R. Hernandez, W.J. Blau, J.N. Coleman, Observation of percolationlike scaling - far from the percolation threshold - in high volume fraction, high conductivity polymer-nanotube composite films, Adv. Mater. 19 (2007) 4443-4447.

[48] G. Horvath, K. Kawazoe, Method for the calculation of effective pore size distribution in molecular sieve carbon, J. Chem. Eng. Jpn. 16 (1983) 470-475.

[49] E.P. Barrett, L.G. Joyner, P.P. Halenda, The determination of pore volume and area distributions in porous substances. I. Computations from nitrogen isotherms, J. Am. Chem. Soc. 73 (1951) 373-380.

[50] S. Brunauer, P.H. Emmett, E. Teller, Adsorption of gases in multimolecular layers, J. Am. Chem. Soc. 60 (1938) 309-319. 
[51] M. Xie, W.E. Price, L.D. Nghiem, M. Elimelech, Effects of feed and draw solution temperature and transmembrane temperature difference on the rejection of trace organic contaminants by forward osmosis, J. Membr. Sci. 438 (2013) 57-64.

[52] X. Xin, G. Xu, H. Li, In Physical and Chemical Properties of Carbon Nanotubes; Suzuki, S., Ed.; InTech: 2013.

[53] B. Benedict, P.E. Pehrsson, W. Zhao, Optically sensing additional sonication effects on dispersed hipco nanotubes in aerated water, J. Phys. Chem. B. 109 (2005) 77787780.

[54] M.F. Islam, E. Rojas, D.M. Bergey, A.T. Johnson, A.G. Yodh, High weight fraction surfactant solubilization of single-wall carbon nanotubes in water, Nano Lett. 3 (2003) 269-273.

[55] D.-Q. Yang, J.-F. Rochette, E. Sacher, Functionalization of multiwalled carbon nanotubes by mild aqueous sonication, J. Phys. Chem. B. 109 (2005) 7788-7794.

[56] A.G. Ryabenko, T.V. Dorofeeva, G.I. Zvereva, UV-vis-NIR spectroscopy study of sensitivity of single-wall carbon nanotubes to chemical processing and van-der-waals SWNT/SWNT interaction. Verification of the SWNT content measurements by absorption spectroscopy, Carbon 42 (2004) 1523-1535.

[57] S. Attal, R. Thiruvengadathan, O. Regev, Determination of the concentration of single-walled carbon nanotubes in aqueous dispersions using uv-visible absorption spectroscopy, Anal. Chem. 78 (2006) 8098-8104.

[58] L. Jiang, L. Gao, J. Sun, Production of aqueous colloidal dispersions of carbon nanotubes, J. Colloid Interf. Sci. 260 (2003) 89-94. 


\section{Supplementary Figures and Tables:}
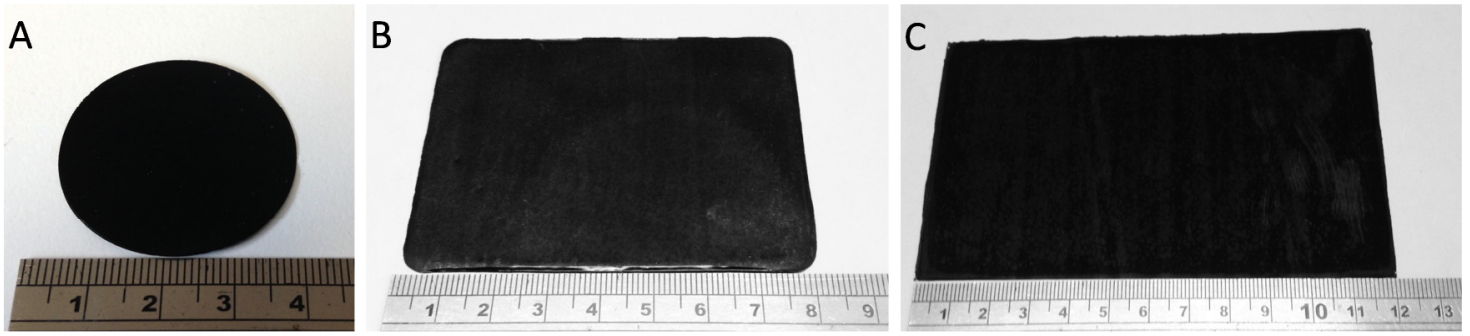

Fig. S1. Photographs of examples of the different types of buckypapers used in this study: (A) small, circular $\mathrm{BP}$ with adiameter of $35 \mathrm{~mm}$; (B) rectangular BP measuring $5.5 \mathrm{~cm} \times 8 \mathrm{~cm}$ and (C) rectangular BP measuring 6 $\mathrm{cm} \times 12 \mathrm{~cm}$.

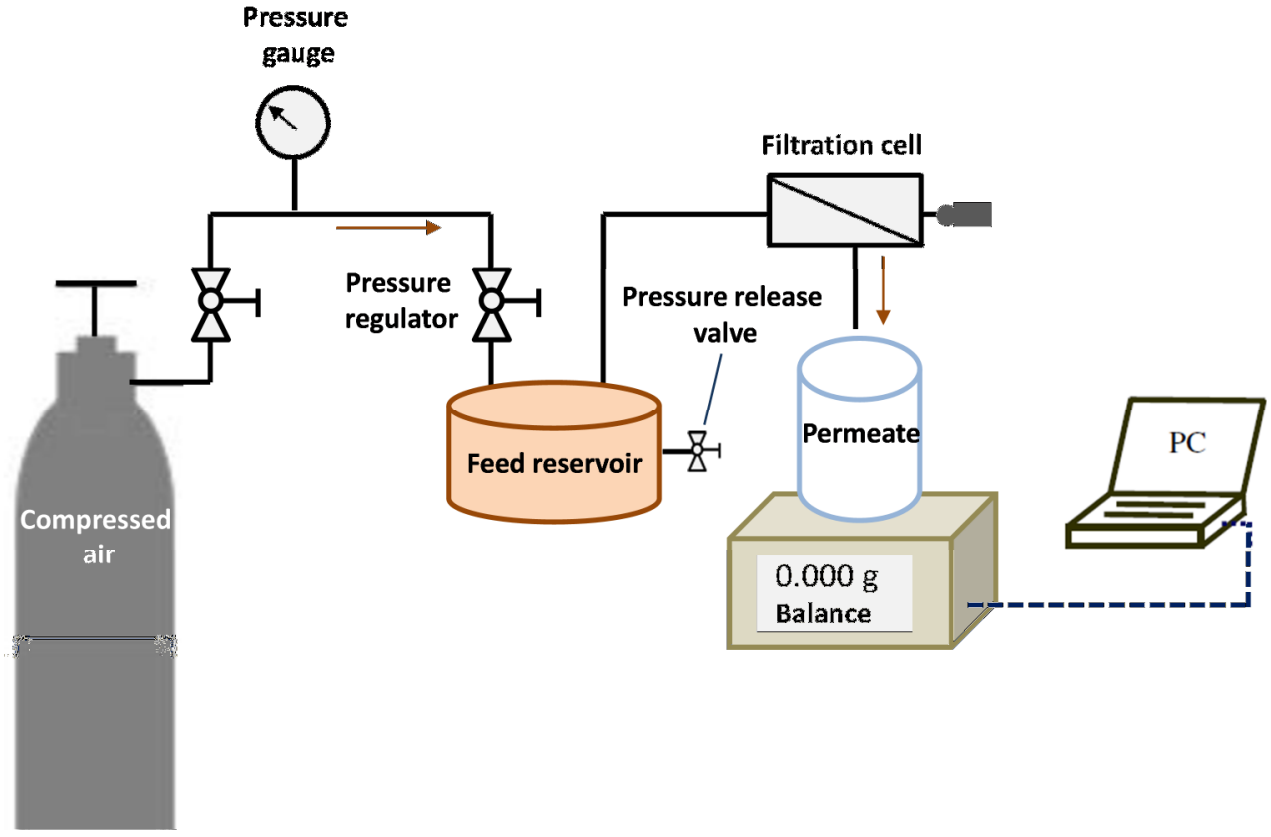

Fig. S2. Schematic illustration of a dead-end filtration setup used to measure the permeability towards water of buckypapers and solute rejection experiments. 


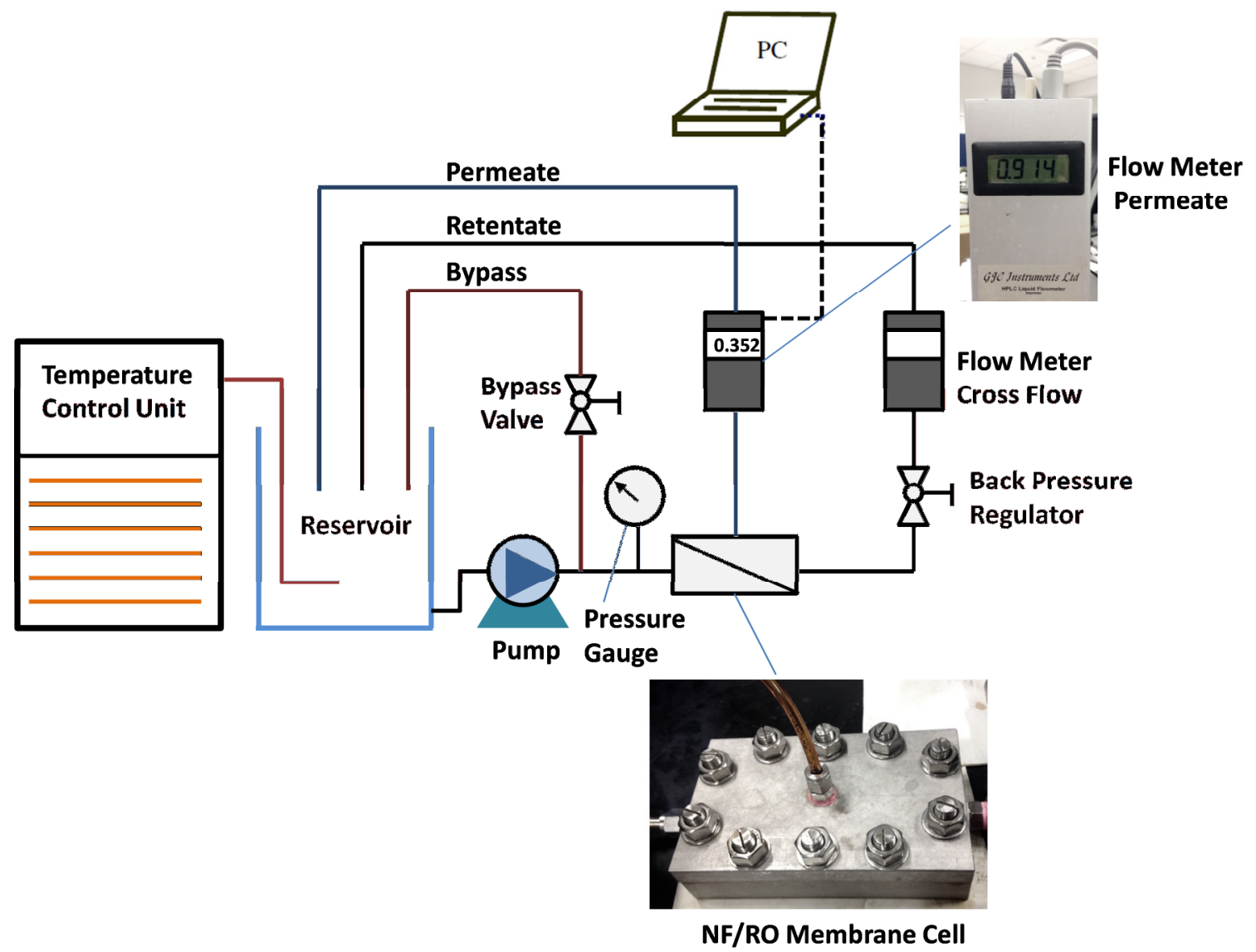

Fig. S3. Schematic illustration of the cross flow filtration system used to perform water and solute permeability experiments.
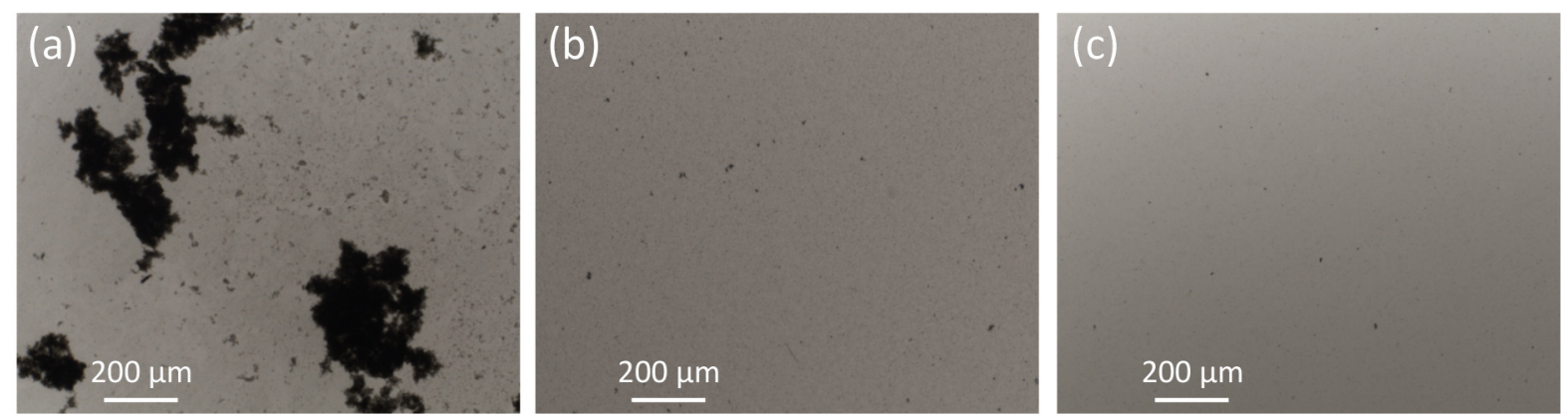

Fig. S4. Optical microscope images of a MWNT/LSZ dispersion that had been sonicated for: (a) 1 min, (b) 10 min and (c) 15 min, taken immediately following sonication. 
(A)

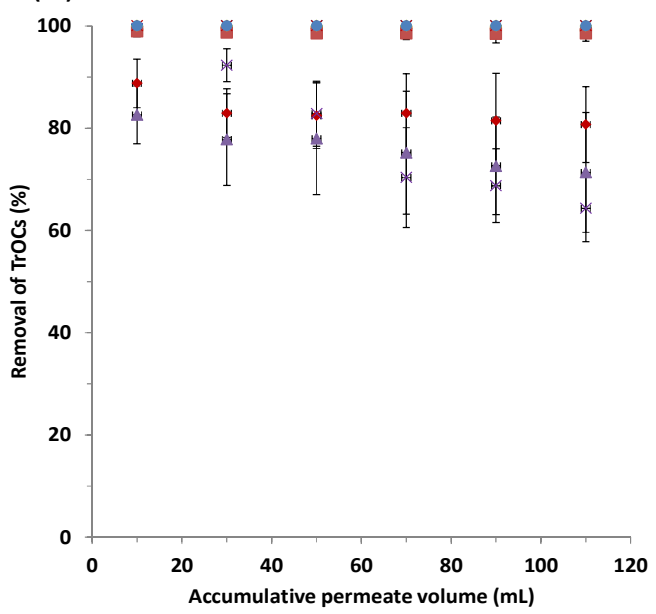

(C)

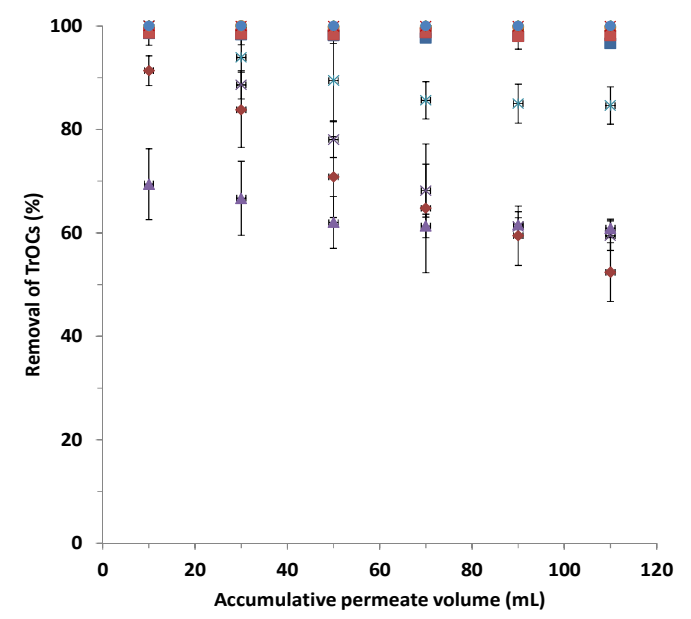

(B)

- Caffeine

- Primidone

$\triangle$ Trimethoprim

$\times$ Sulfamethoxazole

* Carbamazepine

- Bezafibrate

+ Atrazine

- Linuron

- Amitriptyline

$\triangle$ Pentachlorophenol

* Diclofenac

- Triclosan

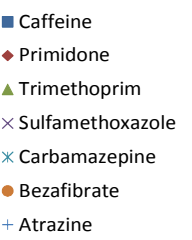

+ Atrazine

- Linuron

- Amitriptyline

$\Delta$ Pentachlorophenol

* Diclofenac

Triclosan

(D)
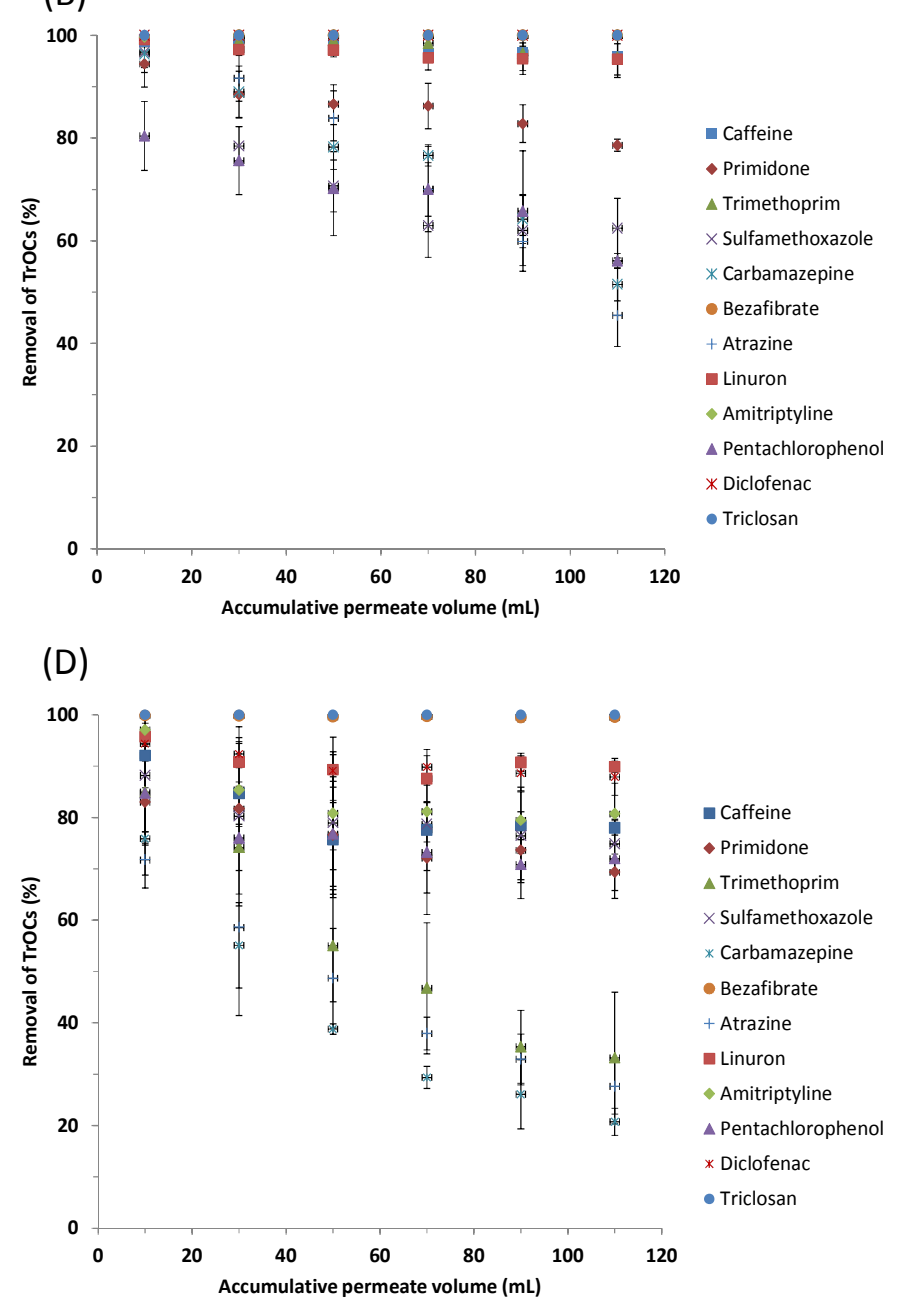

Fig. S5. Effect of time on the removal of trace organic contaminants using different buckypapers: (a) MWNT/CHT, (b) MWNT/BSA, (c) MWNT/DNA and (d) MWNT/LSZ. For each experiment the feed solution contained twelve TrOCs each at a concentration of $50 \mu \mathrm{g} \mathrm{L}^{-1}$. The error bars represent the standard deviations obtained from experiments performed in quadruplicate for all buckypapers except MWNT/LSZ, for which triplicate experiments were performed.

\section{Table S1}

Effect of the initial concentration of biopolymer used during preparation of MWNT/biopolymer dispersions, on the mechanical properties of buckypapers. All dispersions contained MWNTs with a concentration of $0.1 \%$ $(\mathrm{w} / \mathrm{v})$. Values shown are the average of at least 3 samples, with the errors reported determined from the standard deviation obtained from all measurements.

\begin{tabular}{cccccc}
\hline Sample & $\begin{array}{c}\text { Initial } \\
\text { concentration of } \\
\text { dispersant } \\
(\% \mathrm{w} / \mathrm{v})\end{array}$ & $\begin{array}{c}\text { Tensile } \\
\text { Strength } \\
(\mathrm{MPa})\end{array}$ & $\begin{array}{c}\text { Ductility } \\
(\%)\end{array}$ & $\begin{array}{c}\text { Young's } \\
\text { Modulus (GPa) }\end{array}$ & $\begin{array}{c}\text { Toughness } \\
(\mathrm{J} / \mathrm{g})\end{array}$ \\
\hline & 0.2 & $24 \pm 3$ & $2.6 \pm 1.0$ & $0.7 \pm 0.3$ & $0.4 \pm 0.2$ \\
MWNT/BSA & 0.3 & $26 \pm 2$ & $3.7 \pm 0.2$ & $1.5 \pm 0.1$ & $0.4 \pm 0.3$ \\
& 0.4 & $28 \pm 2$ & $4.0 \pm 0.9$ & $1.7 \pm 0.3$ & $0.9 \pm 0.5$ \\
& 0.5 & $44 \pm 3$ & $5.9 \pm 1.0$ & $2.1 \pm 0.1$ & $1.3 \pm 0.3$ \\
& 0.6 & $34 \pm 4$ & $5.0 \pm 0.4$ & $1.8 \pm 0.2$ & $1.1 \pm 0.2$ \\
\hline
\end{tabular}




\begin{tabular}{cccccc} 
& 0.1 & $33 \pm 4$ & $5.8 \pm 1.5$ & $1.1 \pm 0.2$ & $1.8 \pm 0.2$ \\
MWNT/CHT & 0.2 & $36 \pm 3$ & $6.3 \pm 0.8$ & $1.2 \pm 0.1$ & $1.9 \pm 0.7$ \\
& 0.3 & $58 \pm 7$ & $8.1 \pm 1.2$ & $2.1 \pm 0.3$ & $3.3 \pm 0.6$ \\
& 0.4 & $64 \pm 8$ & $10.8 \pm 1.7$ & $2.5 \pm 0.1$ & $4.1 \pm 1.1$ \\
\hline \multirow{3}{*}{ MWNT/GG } & 0.05 & $26 \pm 2$ & $4.0 \pm 0.6$ & $0.6 \pm 0.1$ & $1.7 \pm 0.4$ \\
& 0.1 & $30 \pm 2$ & $5.8 \pm 0.5$ & $1.0 \pm 0.1$ & $1.9 \pm 0.7$ \\
& 0.2 & $41 \pm 5$ & $6.3 \pm 0.7$ & $1.7 \pm 0.2$ & $3.2 \pm 1.1$ \\
MWNT/DNA & 0.3 & $43 \pm 2$ & $8.3 \pm 1.1$ & $2.1 \pm 0.2$ & $4.3 \pm 1.8$ \\
\hline & 0.05 & $14 \pm 2$ & $2.2 \pm 0.7$ & $0.4 \pm 0.1$ & $0.6 \pm 0.2$ \\
& 0.1 & $15 \pm 4$ & $3.4 \pm 0.5$ & $0.6 \pm 0.1$ & $0.9 \pm 0.5$ \\
& 0.2 & $20 \pm 4$ & $4.7 \pm 0.7$ & $0.9 \pm 0.2$ & $1.3 \pm 0.5$ \\
& 0.3 & $26 \pm 5$ & $5.3 \pm 0.4$ & $1.0 \pm 0.3$ & $1.5 \pm 0.5$ \\
\hline
\end{tabular}




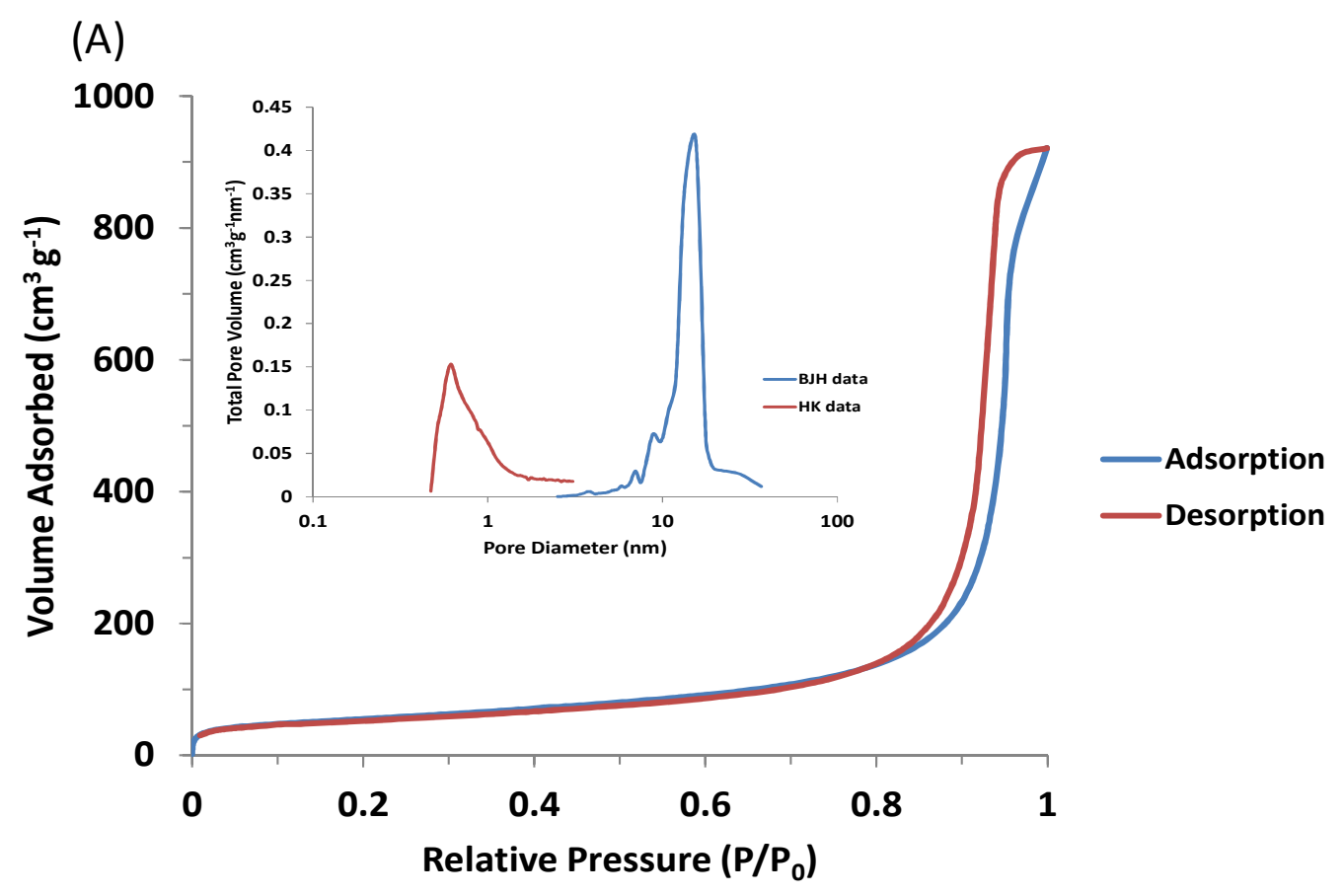

(B)

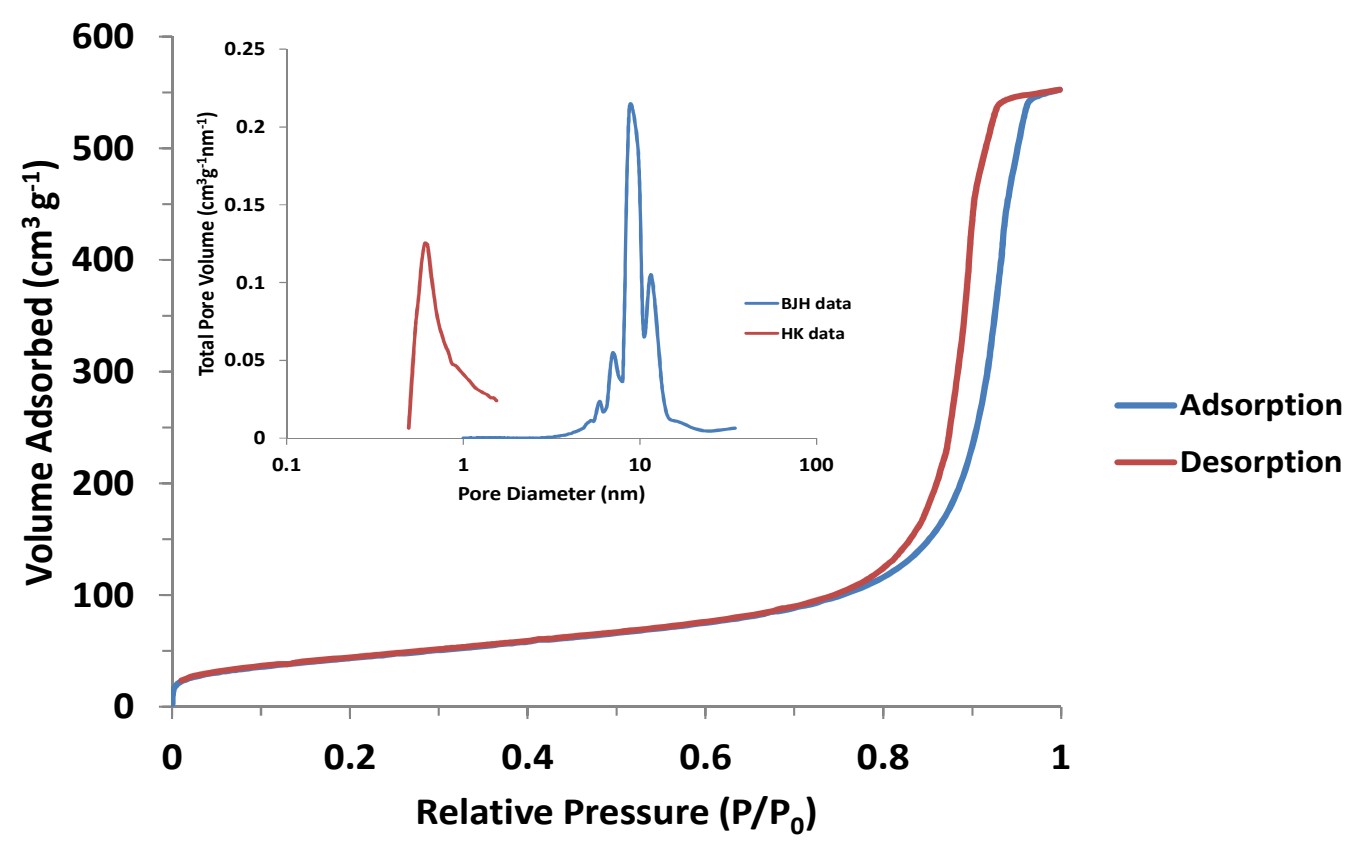

Fig. S6. Nitrogen adsorption and desorption isotherms for: (A) MWNT/CHT and (B) MWNT/LSZ buckypapers. The insets show the pore size distributions for the buckypapers derived from BJH and HK analysis of the isotherms. 


\section{Table S1.}

Effect of the initial concentration of biopolymer used during preparation of MWNT/biopolymer dispersions, on the mechanical properties of buckypapers. All dispersions contained MWNTs with a concentration of $0.1 \%$ $(w / v)$. Values shown are the average of at least 3 samples, with the errors reported determined from the standard deviation obtained from all measurements.

\begin{tabular}{cccccc}
\hline Sample & $\begin{array}{c}\text { Initial } \\
\text { concentration of } \\
\text { dispersant } \\
(\% \mathrm{w} / \mathrm{v})\end{array}$ & $\begin{array}{c}\text { Tensile } \\
\text { Strength } \\
(\mathrm{MPa})\end{array}$ & $\begin{array}{c}\text { Ductility } \\
(\%)\end{array}$ & $\begin{array}{c}\text { Young's } \\
\text { Modulus (GPa) }\end{array}$ & $\begin{array}{c}\text { Toughness } \\
\text { (J/g) }\end{array}$ \\
\hline MWNT/BSA & 0.2 & $24 \pm 3$ & $2.6 \pm 1.0$ & $0.7 \pm 0.3$ & $0.4 \pm 0.2$ \\
& 0.3 & $26 \pm 2$ & $3.7 \pm 0.2$ & $1.5 \pm 0.1$ & $0.4 \pm 0.3$ \\
& 0.4 & $28 \pm 2$ & $4.0 \pm 0.9$ & $1.7 \pm 0.3$ & $0.9 \pm 0.5$ \\
& 0.5 & $44 \pm 3$ & $5.9 \pm 1.0$ & $2.1 \pm 0.1$ & $1.3 \pm 0.3$ \\
& 0.6 & $34 \pm 4$ & $5.0 \pm 0.4$ & $1.8 \pm 0.2$ & $1.1 \pm 0.2$ \\
\hline MWNT/CHT & 0.05 & $28 \pm 2$ & $5.3 \pm 2.7$ & $0.9 \pm 0.3$ & $1.7 \pm 0.3$ \\
& 0.1 & $33 \pm 4$ & $5.8 \pm 1.5$ & $1.1 \pm 0.2$ & $1.8 \pm 0.2$ \\
& 0.2 & $36 \pm 3$ & $6.3 \pm 0.8$ & $1.2 \pm 0.1$ & $1.9 \pm 0.7$ \\
& 0.3 & $58 \pm 7$ & $8.1 \pm 1.2$ & $2.1 \pm 0.3$ & $3.3 \pm 0.6$ \\
& 0.4 & $64 \pm 8$ & $10.8 \pm 1.7$ & $2.5 \pm 0.1$ & $4.1 \pm 1.1$ \\
\hline MWNT/GG & 0.05 & $26 \pm 2$ & $4.0 \pm 0.6$ & $0.6 \pm 0.1$ & $1.7 \pm 0.4$ \\
& 0.1 & $30 \pm 2$ & $5.8 \pm 0.5$ & $1.0 \pm 0.1$ & $1.9 \pm 0.7$ \\
& 0.2 & $41 \pm 5$ & $6.3 \pm 0.7$ & $1.7 \pm 0.2$ & $3.2 \pm 1.1$ \\
& 0.3 & $43 \pm 2$ & $8.3 \pm 1.1$ & $2.1 \pm 0.2$ & $4.3 \pm 1.8$ \\
\hline MWNT/DNA & 0.05 & $14 \pm 2$ & $2.2 \pm 0.7$ & $0.4 \pm 0.1$ & $0.6 \pm 0.2$ \\
& 0.1 & $15 \pm 4$ & $3.4 \pm 0.5$ & $0.6 \pm 0.1$ & $0.9 \pm 0.5$ \\
& 0.2 & $20 \pm 4$ & $4.7 \pm 0.7$ & $0.9 \pm 0.2$ & $1.3 \pm 0.5$ \\
& 0.3 & $26 \pm 5$ & $5.3 \pm 0.4$ & $1.0 \pm 0.3$ & $1.5 \pm 0.5$ \\
\hline
\end{tabular}

